\title{
How Variation of Turbidity of Bleached Oils Characterizes Purity Oil and Bleaching Processes
}

\author{
*Mukasa-Tebandeke I.Z ${ }^{1}$, Wasajja-Navayojo, Z.H ${ }^{1}$, Ssebuwufu, P.J.M ${ }^{1}$.,Wasswa, $\mathbf{J}^{1}$, \\ Nankinga, $\mathbf{R}^{2}$. Lugolobi, $\mathbf{F}^{2}$, Schumann, $\mathbf{A}^{3}$ \\ ${ }^{I}$ Department of Chemistry, School of Physical Sciences, College of Natural Sciences, Makerere University, Box \\ 7062, Kampala Uganda. \\ ${ }^{2}$ Department of Earth Sciences, Wesleyan University, Middletown, USA \\ ${ }^{3}$ Department of Geology, School of Physical Sciences, College of Natural Sciences, Makerere University, Box \\ 7062, Kampala Uganda
}

*Corresponding Author: Mukasa-Tebandeke, 1Department of Chemistry, School of Physical Sciences, College of Natural Sciences, Makerere University, Box 7062, Kampala Uganda.

\begin{abstract}
Freundlich and Langmuir isotherms have always been developed using changes in absorbance of oils. In this study we have investigated use of changes in turbidity of oils to assess bleaching efficiency and develop Freundlich and Langmuir isotherms of bleached oils. Cotton and sunflower oils separately mixed with $1 \%$ acid activated clay and heated to and maintained at thermostated temperature for two hours, filtered and the turbidity of oil recorded using a turbidometer. The adsorptive capacity of clays measured in terms of percentage decrease in turbidity of bleached oil with clay activated by treatment of $25 \%$ sulfuric acid and bleaching performed at $90^{\circ} \mathrm{C}$ were $44 \%, 45 \%, 39 \%$ and $44 \%$ for Budadiri, Chelel, Kajansi, and Mutufu clays respectively. The bleaching efficiency of clay depended on acid concentration and the temperature of the activation which contribute to changes in clay structure. The acid leached clays decreased turbidity of cotton and sunflower seed oils by removing color pigments and other impurities. This was shown by values of $k$ which ranged from -0.8200 to -1.2326 ; and $n$ which ranged from-1.7805 to-4.952 and were in agreement with those published by Topallar (1998).
\end{abstract}

\section{INTRODUCTION}

1.1. Clay

Clays are known to be natural, earthy, fine-grained materials, which develop plasticity when mixed with a limited quantity of water. They belong to a group of minerals collectively called aluminosilicates, containing aluminium oxide and silicon dioxide as universal minerals (Nguetrikam et al, 2008). They are composed principally of silica, alumina and water often with iron, alkali or alkaline earth metals (Parker, 1996). They were classified into phyllosilicates and layers silicates (Logstaffe, 1981) and have for long been used as clarifying agents for vegetable oils for human consumption, filling white paper, drilling fluids, geophagy (Ferrell, 2008) as well as making bricks, tiles, sanitary wares, cups, plates, insulation porcelain Kirabira et al, 2005 and curative (Gichimbi et al, 2012). They are broadly categorized in two groups, kaolinites and smectites. The kaolinites include kaolinite, halloysite, and dickite (Longstaffe, 1981); and the smectites include montimorillonite, nontronite, saponite and hectorite. Clays have different but inter-related structures. Clays never attain the cage structures although their crystalline structures can be very large (Lagaly, 1995). Clays are formed by alteration acid-ingenious rocks or alkali-intrusive magmatic rocks or ashes respectively (Christidis et al, 1995). Smectites consist of two silica tetrahedral sheets for every one octahedral sheet yet kaolinites consist of one to one tetrahedral to octahedral sheets (Lombardi et al, 2002). Clays can be separated into different minerals following the principles of sedimentation and hydrocycloning (Kardy and Amer, 2007). Different clay minerals have different wetting properties and so the have differing densities. Kaolinite is a clay mineral, with the chemical composition $\mathrm{Al}_{2} \mathrm{Si}_{2} \mathrm{O}_{5}(\mathrm{OH})_{4}$ or $\mathrm{Al}_{2} \mathrm{O}_{3}$. $2 \mathrm{SiO}_{2} .2 \mathrm{H}_{2} \mathrm{O}$ (Kerr, 1952). Halloysite is kaolinite with empirical formula $\mathrm{Al}_{2} \mathrm{Si}_{2} \mathrm{O}_{5}(\mathrm{OH})_{4}$ (Kerr, 1952). Illite is clay of formula $\left(\mathrm{K}, \mathrm{H}_{3} \mathrm{O}\right)(\mathrm{Al}, \mathrm{Mg}, \mathrm{Fe})_{2}(\mathrm{Si}, \mathrm{Al})_{4} \mathrm{O}_{10}\left[(\mathrm{OH})_{2},\left(\mathrm{H}_{2} \mathrm{O}\right)(\mathrm{Gates}, 2002)\right.$. Bentonite is clay mineral consisting of montmorillonite, which is either sodium $(\mathrm{Na})$ or calcium $(\mathrm{Ca})$ type depending on dominant exchangeable ion (Kutlic and Sobota, 2012).

International Journal of Advanced Research in Chemical Science (IJARCS)

Page $\mid 36$ 
Nontronite is the iron (III) rich smectite having a chemical composition consisting of more than $30 \%$ $\mathrm{Fe}_{2} \mathrm{O}_{3}$ and less than $\sim 12 \% \mathrm{Al}_{2} \mathrm{O}_{3}$ ignited basis and formula $\mathrm{Ca}_{.5}\left(\mathrm{Si}_{7} \mathrm{Al}_{.8} \mathrm{Fe}_{2 .}\right)\left(\mathrm{Fe}_{3.5} \mathrm{Al}_{4} \mathrm{Mg}_{.1}\right) \mathrm{O}_{20}(\mathrm{OH})_{4}$ (Deer et al, 1992; Gates, 2002). Commonly, kaolinite minerals contain silica 45-56\%, alumina 9-14\%, iron 0-4 \%, calcium or magnesium absent (Jepson and Browser 1975), yet smectites contain silica 20$37 \%$, alumina $10-25 \%$, iron $5-16 \%$, calcium or magnesium $5-15 \%$, sodium or potassium $5-15 \%$ range (Bain, 1986, Gates, 2002). Smectites consist of two silica tetrahedral sheets for every one octahedral sheet yet kaolinites consist of one tone sheets of tetrahedral to octahedral sheets (SouzaSantos, 1989; Tyagi et al, 2006). The transformation of bentonites to illites and kaolinites under the hydrothermal alteration decreases the smectite content via replacement by kaolinite or halloysite and precipitation of various silica polymorphs, carbonates, sulphates and sulphides (Christidis et al, 1995). Many bentonite deposits were formed by in-situ alteration of airborne and water transported volvanic ash in shallow lake and sea water (Jeans 2000; Nadežda et al, 2011; ; Basim 2011). Primary bentonites form by in situ hydrothermal alteration of ultrabasic volcanic glass, ash or feldspar and both smectite and kaolinite rich clays can result from tropical weathering and the acid or basic nature of the environment is the determining factor for the clay type formed (Brigatti et al 2006; Guggenheim et al 2006).

\subsection{Acid Activation}

Activation of clay is a chemical or physicochemical treatment applied to clay to develop capacity to adsorb coloring matter and other impurities in vegetable, animal or petroleum oils (Lamar, 1951). The activity of clay denotes surface chemical and physicochemical reactivity leading to increase in surface area of solid (Gregg, 1992). The purpose of activating clay is producing modifications on surface of material for use as adsorbent for liquid, solid or gas or obtain high rate of reaction or dissolution. Acid activation involves removal of exchangeable interlayer ions as well as dissolution of tetrahedral and octahedral ions from alumina and silica layers (Vanzuela-Diaz and Souza-Santos, 2001) and replaces them with hydrogen causing structural deformations. The mineral composition and texture of acid-leached clays changes (Foletto et al, 2011; Franus et al, 2004; Rozie et al, 2010). Methods used to enhance or to activate the properties of a natural clay or clay mineral for several industrial uses; physical - alteration of particle size (specific surface area) mechanically; thermal - alteration of chemical composition and/or crystalline structure by the effect of temperature; chemical usually limited to ionic exchange: therefore, it does not include massive chemical destruction of the clay mineral structure; pillaring which is chemical and physical restructuring of the clay mineral structure to increase capacity for adsorption or to make spaces that encourage adsorption of specific ions. Bleaching is an adsorption process in oil refining and the most critical stage since it helps to improve the appearance, flavor, taste and stability of the final oil products by removing colored and colorless pigments from the oil (Didi et al, 2009; Usman et al , 2013; Farihahusnah et al, 2011). The acid activated bentonites were suitable for decolorization of cottonseed oil through removing carotene and chlorophyll with bleaching capabilities of up to $88.9 \%$ (Zhansheng et al, 2006). High bleaching performance of bleaching earth was found to depend on acid concentration, contact time and the temperature of the activation process (Farihahusnah et al, 2011; Usman et al, 2013; Makhoukhi et al, 2008).

\subsection{Vegetable Oil}

A vegetable oil is a triglyceride extracted from a plant. A triglyceride, triacylglycerol, or triacylglyceride is an ester derived from glycerol and three fatty acids (Nomenclature of Lipids, 2006). Triglycerides are the main constituents of vegetable oil are typically more unsaturated and animal fats are typically more saturated (Nelson and Cox, 2000). Triglycerides are formed by combining glycerol with three fatty acid molecules. Alcohols have a hydroxyl group. Organic acids have a carboxyl group. Alcohols and organic acids join to form esters. The glycerol molecule has three hydroxyl groups. Each fatty acid has a carboxyl group. In triglycerides, the hydroxyl groups of the glycerol join the carboxyl groups of the fatty acid to form ester bonds:

$\mathrm{HOCH}_{2} \mathrm{CH}(\mathrm{OH}) \mathrm{CH}_{2} \mathrm{OH}+\mathrm{RCO}_{2} \mathrm{H}+\mathrm{R}^{\prime} \mathrm{CO}_{2} \mathrm{H}+\mathrm{R}^{\prime \prime} \mathrm{CO}_{2} \mathrm{H} \rightarrow \mathrm{RCO}_{2} \mathrm{CH}_{2} \mathrm{CH}\left(\mathrm{O}_{2} \mathrm{CR}^{\prime}\right) \mathrm{CH}_{2} \mathrm{CO}_{2} \mathrm{R}^{\prime \prime}+3 \mathrm{H}_{2} \mathrm{O}$

Such oils have been part of human culture for millennia (4,000-year-old 'kitchen' unearthed in Indiana, 2006). The term vegetable oil can be narrowly defined as referring only to plant oils that are liquid at room temperature (Parwez, 2006) or broadly defined without regard to a substance's state of matter at a given temperature (Robin, 1999). Vegetable oils are composed of triglycerides, as 
contrasted with waxes which lack glycerin in their structure. Although many plant parts may yield oil in commercial practice, oil is extracted primarily from seeds. There are many triglycerides: depending on the oil source, some are highly unsaturated, some less so. Saturated compounds are saturated with hydrogen; all available places where hydrogen atoms could be bonded to carbon atoms are occupied. Unsaturated compounds have double bonds $(\mathrm{C}=\mathrm{C})$ between carbon atoms, reducing the number of places where hydrogen atoms can bond to carbon atoms. Saturated compounds have single bonds $(\mathrm{C}-\mathrm{C})$ between the carbon atoms, and the other bond is bound to hydrogen atoms (for example $=\mathrm{CH}-\mathrm{CH}=,-\mathrm{CH}_{2}-\mathrm{CH}_{2}$, etc.). Example of an unsaturated fat triglyceride is shown below. Left part: glycerol, right part from top to bottom: palmitic acid, oleic acid, alpha-linolenic acid. Chemical formula: $\mathrm{C}_{55} \mathrm{H}_{98} \mathrm{O}_{6}$

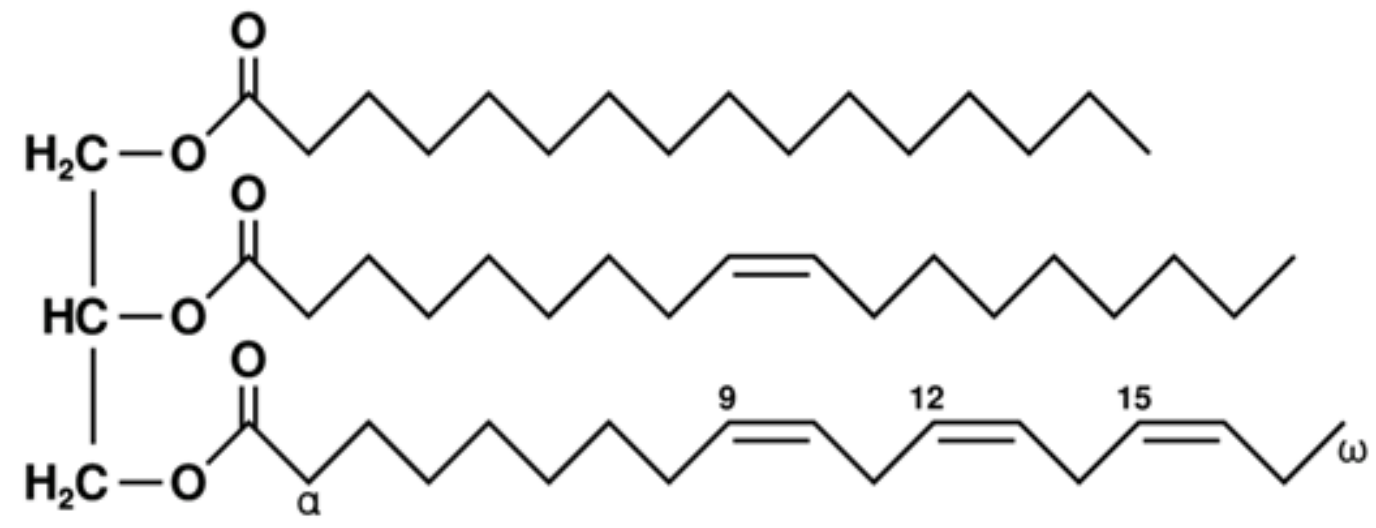

Sunflower-seed, cotton-seed, Olive, corn, soybeans and all other seed oils fall in the general family of oils known as vegetable oils.

The purpose of refining oil is to eliminate impurities present in crude oils in order to obtain high quality oil. The refining processes improve the appearance and flavor as well as chemical stability. However, in Japan, USA and European countries, the nutritional quality of edible oils is becoming is becoming important. Refining has the purpose of not only eliminating phospholipids, free fatty acid, peroxides, polymers, pigments and secondary oxidation products, but also minimizing free fatty acids formation and tocopherols (Kellen, 1997). Typical oil refining processes include degumming, chemical or physical refining, bleaching and deodorization (Ericson, 1995). During deodorization, thermal degradation of vegetable oils may occur, the double bond may isomerize from cis to trans (Ackman et al, 1974) and tocopherols may be lost (Ferrari et al, 1996). Tocopherols are important lipid oxidation inhibitors in food and biological systems (Kamal-Eldin, and Appelqvist, 1996). However, tocopherols are drastically reduced during degumming, refining, bleaching and deodorization Ferrari et al 1996; Kellen, 1997).

Formation of turbidity in canola oil was facilitated with addition of acetone, and a method to measure the sediment content based on the oil turbidity has been developed. Canola oil was mixed with acetone at the ratio of 60:40, and the turbid solution developed in an ice bath for $20 \mathrm{~min}$. The turbidity of the oil solution was determined using a turbidometer. The relation between turbidity of the oil solution and sediment content was nonlinear and could be correlated by a second-order polynomial. There was no difficulty in the development of turbidity in canola oil solutions in the presence of added lecithin $(2 \%$ w/w). However, with added lecithin, turbidity was $23 \%$ higher at the same sediment content (Hua Liu et al, 1996).

Various minor components of vegetable oils will have a significant impact on soy oil oxidative stability, and the amount of these various minor components decreases as degree of processing increases (Jain et al, 2008a, 2008b). The reason for refining vegetable oils is to remove substances that reduce oil quality (Jawad, 1983). The steps of refinement are degumming, bleaching, winterizing, steam distillation, neutralizing, and deodorizing (Hoffman, 1989). Minor components that are removed in these stages include tocopherols, pigments especially carotenoids like lutein, and phospholipids (Lindley, 1998). The tocopherol content of oils is dependent on plant genotype, climate conditions, and processing and storage conditions (Rabascall and Riera, 1987). Very low concentrations of tocopherols are sufficient to protect vegetable oils from oxidation. Usually one tocopherol molecule can protect between 103 and 108 polyunsaturated fatty acid molecules (Kamal-Eldin et al, 1996. The natural antioxidants are removed during each step of the oil refining process (Kellens, 1997). It is also known that the various refining steps may affect oxidative stability of vegetable oils. 
The average loss of total tocopherol content during the refining process was found to be greater than $30 \%$. Carotenes and xanthophylls, chlorophyll, diketones, and browning products are carotenoid pigments, but lutein and other carotenoids are known for their ability to protect against oxidation by absorbing light and preventing photo-oxidation (Choe and Min, 2006).

Oil turbidity is a measure of cloudiness in a liquid. Oil components that contribute to turbidity include saturated triglycerides, waxes, free fatty acids, hydrocarbons, and sterols (Popov et a!, 1970; Morrison and Robertson, 1975). These components are present in refined, bleached, and deodorized oils in parts per million and parts per billion concentrations, making their removal difficult (Morrison and Robertson, 1975). Studies on vegetable oil turbidity particularly implicate sunflower oil mainly due not only to its wax content but also its saturated fatty acids, especially stearic and palmitic acid (Leibovitz and Ruckenstein, 1981). The wax content in sunflower oil decreases with degree of processing (Leibovitz and Ruckenstein, 1984) and may vary with seed variety, geographical growing area, and seasonal growing conditions. However even other oils may have varying turbidity. Turbidity can be determined by measuring absorbance at $600 \mathrm{~nm}$. The reduction in turbidity of bleached oils can be a good measure of the extent bleaching and efficiency or performance of the process of bleaching. The maximum antioxidant activity is observed between 3 and $60 \mathrm{ppm}$. The removal of these phospholipids will result in the removal of metals like iron and copper, increasing the oxidative stability of the processed oils, though the mechanism of this action is not well understood. Degumming reduces the phosphorus content of the oil from 500-900 ppm to $12-170 \mathrm{ppm}$, similarly reduction occurs in turbidity of oils.

It was reported that in European countries, the quality parameters for refined edible oils include low levels of trans fatty acids (TFA) $<1 \%$ and high retention of tocopherols because of their health implication (Ahrens, 1998; Aro et al, 1998). Deodorization conditions have been set such that tocopherols loss never exceeds $25 \%$ (Kellens, 1997). The processing conditions should be carefully evaluated in order to reduce the loss of tocopherols and the formation of TFAs during refining (Medina-Juarez et al, 2000). The transmittance of 20 per cent oil in acetone improved from 37 to 57 per cent at $570 \mathrm{~nm}$ (Volotovskay et al, 1974), there was also marked reduction in color of rice bran oil by destruction of pigments. The process of degumming of dewaxed rice bran oil had little or no effect on its specific gravity, refractive index, smoke point, acid value and peroxide value. Degumming of dewaxed rice bran oil reduced its phospholipids content from 3.90 to 0.51 per cent, similarly its absorbance and turbidity decreases.

\subsection{Adsorptive Bleaching}

An isotherm is the expression of the relationship between the partial pressure of adsorbate gas, or solute concentration in solution, and the surface coverage of the adsorbent at a constant temperature (Gregg and Sing, 1997). The Langmuir isotherm has been used to describe the oil pigment adsorption and adsorption of other minor oil solutes during oil processing. A plot of $\mathrm{p} / \mathrm{n}$ against $\mathrm{p}$ gives a linear relation (Yuksel, 2003). The Langmuir isotherm has been applied to pigment adsorption from vegetable oil. The distribution of coloring materials and other pigments between the liquid phase and adsorbent is a measure of equilibrium position in the sorption process and can generally be expressed by one or more series of isotherms (Kaynak et al, 2004). In this study, the turbidity and sorption characteristics of color, chlorophyll and carotene pigments onto the clay adsorbents can be mainly discussed on the basis of Freundlich and Langmuir isotherms (Kaynak et al, 2004). The removal of the main coloring pigments (chlorophyll, $\beta$-carotene and red color) in neutralized sunflower and/or cotton oils with different types of bleaching earth materials has been examined in a pilot system at temperature of $105{ }^{\circ} \mathrm{C}$ and pressure of $50 \mathrm{mmHg}$ and bleaching earth dosage (Topallar, 1998; Ujeneza et al, 2014; Topkafa et al, 2013).

Freundlich (1906) developed equation 1.1 relating adsorption to residual solute concentration. $x / m=k C^{n}$

The bleaching capacity of an adsorbent and its characteristic manner of adsorption may be described, respectively, by the $\mathrm{k}$ and $\mathrm{n}$ parameters defined by Freundlich (Rossi et al, 2003).

Langmuir (1916) showed the distribution of adsorbed molecules over the surface in form of unimolecular layer and at the dynamic equilibrium between adsorbed and free molecules the relation in equation 1.2 is true. 


$$
\frac{p}{x / m}=(1 / a)(b / a) p
$$

Where $\mathrm{p}$ is equilibrium pressure for substance adsorbed, $\mathrm{x}$ is the amount of substance adsorbed, $\mathrm{m}$ is the amount of adsorbent, and $\mathrm{a}$ and $\mathrm{b}$ are constants.

As absorbance and turbidity measurements can be taken in all experiments involving the bleaching processes, the relative quantity of pigment adsorbed, $\mathrm{x}$ and the residual relative quantity at equilibrium, Xe are obtained from equations 1.1 and 1.2 (Boki, et al, 1994).

$$
\begin{aligned}
& x=\frac{(A o-A t)}{A o} \\
& X e=\frac{A t}{A o}=1-x
\end{aligned}
$$

Where Ao is the absorbance of unbleached crude oil and At is absorbance of bleached oil at time t.

Using equations 1.3 and 1.4 and writing $\mathrm{Xe}$ instead of equilibrium pressure, $\mathrm{P}$ gave equations 1.5 and 1.6 (Achife and Ibemesi, 1989).

$$
\begin{aligned}
& \frac{X e}{x / m}=(1 / a)+(b / a) X e \\
& x / m=K X e^{n}
\end{aligned}
$$

The heat of adsorption, $\triangle H a$, may be calculated in a manner similar to that used to calculate the heat of vaporization of a liquid using the following modification of the Clausius- Clapeyron equation (Smith, 1970):

$d(\ln P) / d T=\Delta H a / R T^{2}$

Integration of equation 1.7 gives;

$\ln P=-\Delta H a / R T+c$

Where $c$ is constant of integration.

For the bleaching process, Equation 1.8 can be written as follows;

$\ln X e=-\Delta H a / R T+c$

The heat of adsorption, $\Delta H a$, is given by product of slope and gas constant.

Boki et al, (1992) have applied the Langmuir and Freundlich equations to the adsorption isotherms of $\beta$ - carotenes on montmorillonite, activated clay and sepiolite from alkali- refined rapeseed and soybean oils. Application of Langmuir and Freundlich equations to adsorption isotherms for bleaching of crude sunflower seed oil with bentonite and showed that absorbance of bleached sunflower oil decreased as the concentrations of bentonite increased with increase in temperature between 60 and 90 ${ }^{\circ} \mathrm{C}$ (Kara et al, 2008; Topallar, 1998; Ujeneza et al, 2014). In this study we examine the use of variation of turbidity of bleached oils in describing Freundlich and Langmuir isotherms in bleaching of oils using Ugandan clays.

The vegetable oils are bleached to remove impurities like coloring materials, trace metals and bad odor so as to improve sensory quality and oxidative stability of deodorized oils (De Greyt and Kellen, 2000). This study has investigated variation of turbidity of bleached oils as a measure to establish the quality of bleached cotton and sunflower oils.

\section{Materials AND Methods}

\subsection{Sampling Methods}

Four composite clay samples were collected from Kajansi, Mutufu, Budadiri and Chelel. The samples were respectively labeled A, B, C and D. The samples were collected at depths in range of $35-150$ $\mathrm{cm}$ from the surface to minimize the effect of weathering and contamination.

\subsection{Preparation of Clays}

Raw samples of clays were separately soaked in distilled water, sieved to pass through a mess $5.3 \mathrm{x}$ $10^{-4} \mathrm{~m}$ diameter to exclude silica and sand stones, dried and ground to powder using a rolling mill. Experiments were performed in triplicate. The clay was washed with plenty of distilled water to remove contaminants. After drying in the oven at $105{ }^{\circ} \mathrm{C}$, it was ground to pass through $200 \mu \mathrm{m}$ mesh sieve. The chemical and mineralogical composition of raw clays were reported in earlier studies (Mukasa-Tebandeke et al, 2006; Donald and Quirine, 2012), moisture (Usman et al, 2012). 


\subsection{Leaching of Clays}

Clay powder $(10.0 \mathrm{~g}, 0.02 \mathrm{~mol})$ was mixed with acid $(50.0 \mathrm{~mL})$ of appropriate concentrations $(5,10$, $20,25 \% \mathrm{v} / \mathrm{v}$ ) in a flask. The mixture was heated at $105^{\circ} \mathrm{C}$ for 4 hours; then cooled and filtered. The residue was washed to neutrality with distilled water; then dried at $105^{\circ} \mathrm{C}$ in the thermo-stated oven (Kutlic et al, 2012; Nadezda et al, 2011). The dried leached powders were re-ground, labeled and stored for future use. The activated clay samples form Kajansi were labelled A1, A2, A3 and A4 where the numbers in these labels referred to the concentrations of the acid used. Those from Budadiri, Mutufu and Chelel were respectively designated as B, C and D with 1, 2, 3, 4 designating the strength of acid used to leach the clay in respective strength of 5. 10,20 and 25\%. All samples of activated clay were stored in polyethylene bags for bleaching studies.

\subsection{Degumming of Vegetable Oils}

Crude oil (100.0 g, $0.43 \mathrm{~mol})$ was placed in a flask, $85 \%$ phosphoric acid $(1.0 \mathrm{~g}, 0.1 \mathrm{mmol})$ was added, the mixture heated at $90^{\circ} \mathrm{C}$ while stirring at 900 revolutions per minute for 10 minutes under nitrogen blanket. The oil was filtered under nitrogen. This method was reported by Car (1978) and modified by Saadia (1992).

\subsection{Adsorption Isotherms of Bleached Oil}

Mixture of the appropriate alkali-refined crude oil (100.0 g) and appropriate clay powders $(1.0 \mathrm{~g})$ was placed in $250 \mathrm{~cm}^{3}$ Pyrex glass vacuum flask fitted with a magnetic stirrer, connected to a vacuum pump. The flask was immersed in a thermo-stated iso-electric mantle at temperatures, 40, 50, 60, 70, 80, 90,100, 110, 120 and $130{ }^{\circ} \mathrm{C}$ (Patterson, 1992). The mixture was heated while stirring continuously for a further two hours at the set temperature under high vacuum $(8.5 \mathrm{kPa})$. The hot oil and clay mixture was filtered in nitrogen atmosphere and tested by measuring its turbidity (Kaynak et al, 2004).

\subsection{Turbidity}

The turbidity of bleached and unbleached oil was determined using a Jenway turbidometer (model 6035) in the wavelength range of 550-600 nm (AOCS, 1981, Turkulov et al, 1986).

\subsection{Bleaching Efficiency}

The turbidity of bleached and unbleached oils was measured using Jenway turbidometer. Bleaching capability or efficiency was evaluated using the following formula (Srasra et al, 1989).

$\mathrm{BE}=100($ To-Ts $) /$ To

Where To is the turbidity of unbleached oil, Ts is turbidity of bleached oil and BE is bleaching capability.

Bleaching of oils by adsorption removes some pigments. It has been well accepted that carotenoids, chlorophyll, squalenes, tocopherols and other pigments are the main solids present in vegetable oils; removal of these pigments decreases turbidity of bleached oils.

\section{RESULTS AND DISCUSSION}

Chemical analyses of clays used in this study were determined and published in earlier papers (Mukasa-Tebandeke et al, 2015). And in another study, clay sampled at A was shown to averagely contain $\approx 59 \pm 0.045 \%$ silicon dioxide, $20 \pm 0.045 \%$ aluminium oxide, $9 \pm 0.045 \%$ iron oxide and other elements (Nyakairu et al, 2002). However, clays from magmatic sediments, B, C and D contained major elements with relatively high magnesium oxide, ranging from 23.9 to $40.4 \%$ and low silicon dioxide and aluminium oxide, ranging from 12.8 to $29.0 \%$ (Herzig et al, 1998) and their data confirms the data we have adduced in this study on clays from B, C, and D which are associated with volcanic margins of Mountain Elgon. The loss on ignition of the selected clays used in this study lie in the range from $6-10 \%$ an indication that heating clays to $105^{\circ} \mathrm{C}$ results in loss of structural water from the clay (Ball, 1964). The reactions occurring in the clay materials include dehydration and dehydroxilation of soil used. Formulae and names of selected clays were $\mathrm{A}$ was kaolinites in mixture with smectite, $\mathrm{Al}_{2} \mathrm{Si}_{2} \mathrm{O}_{5}(\mathrm{OH})_{4}$. mixed with $\mathrm{Ca}_{5}\left(\mathrm{Si}_{7} \mathrm{Al}_{.8} \mathrm{Fe}_{2 .}\right)\left(\mathrm{Fe}_{3.5} \mathrm{Al}_{4} \mathrm{Mg}_{.1}\right) \mathrm{O}_{20}(\mathrm{OH})_{4}$ and silica $\mathrm{SiO}_{2 ;} \mathrm{B}$ and $\mathrm{C}$ were nontronite $\mathrm{Ca}_{5}\left(\mathrm{Si}_{7} \mathrm{Al}_{.8} \mathrm{Fe}_{2 .}\right)\left(\mathrm{Fe}_{3.5} \mathrm{Al}_{4} \mathrm{Mg}_{.1}\right) \mathrm{O}_{20}(\mathrm{OH})_{4}$ with $\mathrm{SiO}_{2}$; D was nontronite mixed with kaolinites, $\mathrm{Na}_{0.33}\left(\mathrm{Mg}, \mathrm{Fe}^{+2}\right)_{3}(\mathrm{Si}, \mathrm{Al})_{4} \mathrm{O}_{10}(\mathrm{OH})_{2} \cdot 4 \mathrm{H}_{2} \mathrm{O}_{4} \mathrm{H}_{2} \mathrm{O}$ and $\mathrm{Ca}_{5}\left(\mathrm{Si}_{7} \mathrm{Al}_{.} \mathrm{Fe}_{.2}\right)\left(\mathrm{Fe}_{3.5} \mathrm{Al}_{4} \mathrm{Mg}_{.1}\right) \mathrm{O}_{20}$ $(\mathrm{OH})_{4}$ (Gates, 2002). 
The vegetable oils are bleached to remove impurities like coloring materials, trace metals and bad odor so as to improve sensory quality and oxidative stability of deodorized oils (De Greyt and Kellen, 2000). This study has investigated variation of turbidity of bleached oils as a measure to establish the quality of bleached oils. The turbidity for unbleached, crude sunflower-seed and cotton-seed oils were respectively determined to be 6.580 and 7.383 .

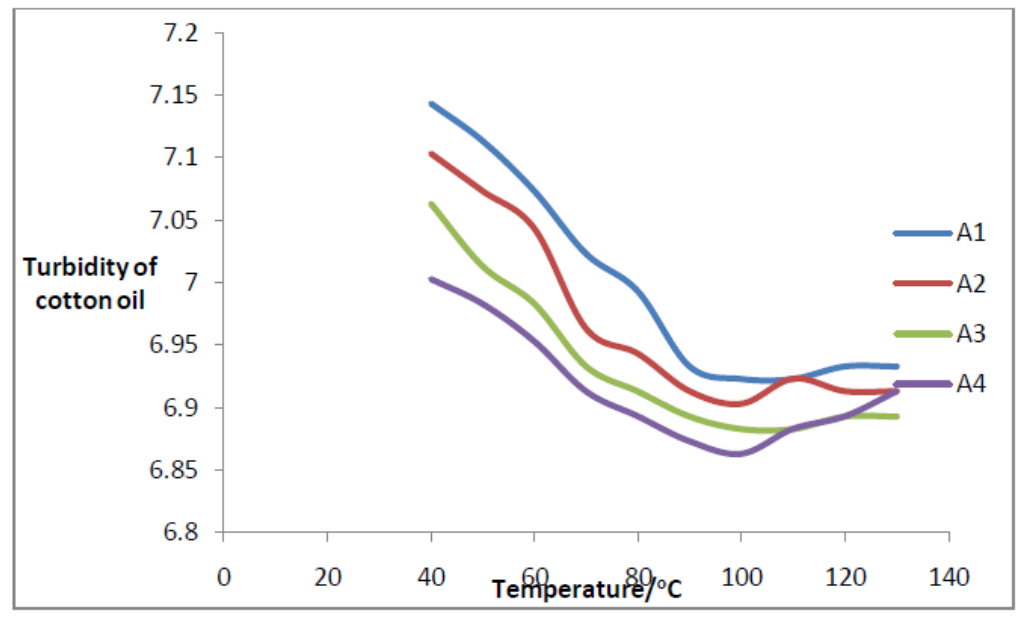

Figure1a. Representative plot of variation of turbidity of bleached cotton oil against temperature

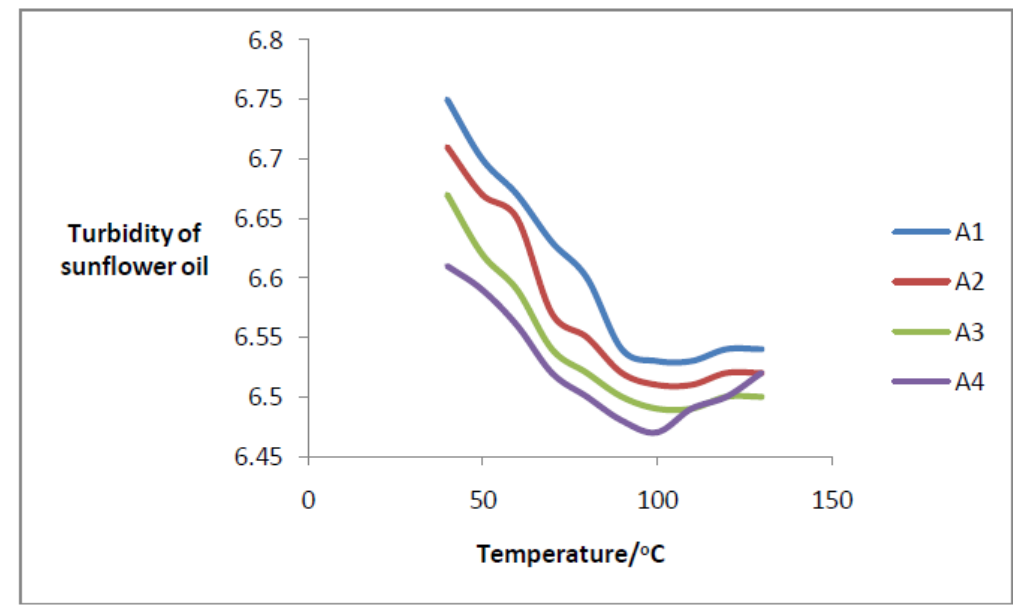

Figure1b. Representative plot of variation of turbidity of bleached sunflower oil against temperature of activation

As shown in Figures 1a and 1b, the values of turbidity decreased as the concentrations of the acid used to leach the clays increased. This showed that best bleaching clay was obtained when acid of higher strength had been used to leach the clay. As leaching removed octahedral ions form clay lamellas leaving a silicon dioxide skeleton with many sites over which adsorption of solids like color bodies and pigments adhered. The turbidity values also decreased as the temperatures at which the clay matrices had been thermally activated increased. High temperatures have capacity to dehydrate and dehydroxylate clays exposing silica on the surface of the clay and increasing bleaching ability of the clay which decreased cloudiness of the oils. Hence turbidity decreased as temperature increased. Thus demonstrating that acid-leaching and thermal activation improved the capacity of the clays to hold back colored impurities and solids in the oils (Boyd, 1988).

However, clays activated at temperatures above $120{ }^{\circ} \mathrm{C}$ bleached oils with higher turbidity values than those activated at lower temperatures because activation at higher temperatures removed the crystalline water of the clay matrices (Dandy, 1965) leading to formation of larger pores in the clay matrix. So some colored impurities readily eluted with the oils. Loss of water of crystallinity retards the bleaching capacity of the clay because the water or hydroxyl groups in the clay matrices facilitate bleaching through exchange of ions (Balaras et al, 1999).

Bleaching involves adsorption of coloring matter and other impurities on bleaching earths. Therefore a comparison between the color and turbidity of bleached and unbleached oils is of great importance, can be best presented in form of adsorption isotherms. The isotherms portray what takes place in the entire bleaching process at various temperatures. Adsorption isotherms of pigments from alkali International Journal of Advanced Research in Chemical Science (IJARCS)

Page $\mid 42$ 
refined oils were presented showing that Freundlich and Langmuir equations can be used to elucidate adsorption characteristics of pigments on clays and sepiolites (Boki et al, 1992).

The color and turbidity of bleached and unbleached sunflower-seed and cotton-seed oils have been used to study the nature and extent of adsorption of the impurities in crude oils on clay materials (Mbah, 2005; Topallar, 1998). The decrease in turbidity of cotton and sunflower seed oils on being bleached has been explained in a similar way to what Hui (1996) noted when they separately observed the $5-20 \%$ reduction in the red color of soybean,

canola and palm oils occurred during the bleaching with acid activated bleaching earths. They noted that a breakdown occurs in chlorophyll and carotene concentrations for which it was concluded that the increase in adsorption activity of clays after acid treatment is due to the weakness of the Si-O bonds in the clay structure (Hui, 1996). Basing on turbidity, the bleaching efficiency of the clays A, $\mathrm{B}, \mathrm{C}$ and $\mathrm{D}$ increased with increase in mass percent of acid and temperature as shown in Table 1 . The increase in bleaching performance resulted from progressive removal of octahedral cations from the clay as the concentration of acid increased leaving a silicon-oxygen skeleton on to which impurities adsorbed with ease.

Table1. Bleaching efficiency, $B E$

\begin{tabular}{|c|c|c|c|c|c|c|c|c|c|c|c|c|}
\hline & A1 & A2 & A3 & A4 & C1 & C2 & C3 & C4 & D1 & D2 & D3 & D4 \\
\hline $\begin{array}{c}\text { Temp/ } \\
{ }^{\circ} \mathrm{C}\end{array}$ & BE\% & SE\% & BE\% & BE\% & BE\% & BE\% & BE\% & BE\% & BE\% & BE\% & BE\% & BE\% \\
\hline 40 & 7.0 & 11.0 & 15.0 & 21.0 & 9.0 & 15.0 & 21.0 & 28.0 & 12.0 & 16.0 & 22.0 & 29.0 \\
\hline 50 & 10.0 & 14.0 & 20.0 & 23.0 & 12.0 & 18.0 & 26.0 & 31.0 & 15.0 & 19.0 & 27.0 & 32.0 \\
\hline 60 & 14.0 & 17.0 & 23.0 & 26.0 & 15.0 & 20.0 & 29.0 & 34.0 & 19.0 & 22.0 & 30.0 & 34.0 \\
\hline 70 & 19.0 & 25.0 & 28.0 & 30.0 & 22.0 & 21.0 & 34.0 & 37.0 & 24.0 & 30.0 & 35.0 & 39.0 \\
\hline 80 & 22.0 & 27.0 & 30.0 & 32.0 & 24.0 & 29.0 & 36.0 & 39.0 & 27.0 & 32.0 & 37.0 & 41.0 \\
\hline 90 & 28.0 & 30.0 & 32.0 & 34.0 & 30.0 & 33.0 & 38.0 & 43.0 & 33.0 & 35.0 & 39.0 & 44.0 \\
\hline 100 & 29.0 & 31.0 & 33.0 & 35.0 & 31.0 & 32.0 & 39.0 & 44.0 & 34.0 & 36.0 & 40.0 & 45.0 \\
\hline 110 & 29.0 & 31.0 & 33.0 & 33.0 & 29.0 & 31.0 & 39.0 & 40.0 & 34.0 & 36.0 & 40.0 & 42.0 \\
\hline 120 & 28.0 & 30.0 & 32.0 & 32.0 & 28.0 & 30.0 & 38.0 & 39.0 & 32.0 & 34.0 & 39.0 & 42.0 \\
\hline 130 & 28.0 & 30.0 & 32.0 & 30.0 & 28.0 & 30.0 & 36.0 & 37.0 & 32.0 & 34.0 & 39.0 & 40.0 \\
\hline
\end{tabular}

Highest bleaching efficiency observed for cotton oil was $45 \%$ when bleaching was carried out at 100 ${ }^{\circ} \mathrm{C}$ using clay leached in $25 \%$ sulfuric acid. This has been used to assert that optimum bleaching is attained at this temperature because energy needed to activate the clay surface would have been gained by the clay at that temperature. Since calculation for Xe used in Langmuir isotherms necessitated knowing value of $\mathrm{x}$, the decrease in turbidity of oil caused by bleaching, it has been observed that the value of $\mathrm{x}$ increased with increase in temperature and mass percent of acid used from $8 \%$ to $26 \%$ for oil bleached at $40{ }^{\circ} \mathrm{C}$ using clay D and $30 \%$ to $40 \%$ for oil bleached at $100{ }^{\circ} \mathrm{C}$. The bleaching efficiency for clay $\mathrm{C}$ operating at $40{ }^{\circ} \mathrm{C}$ increased from 9 to $23 \%$ yet at $100{ }^{\circ} \mathrm{C}$ it increased from 23 to $37 \%$.

The turbidity for unbleached, crude sunflower-seed and cotton-seed oils were respectively determined to be 6.580 and 7.383. The values of turbidity for the bleached sunflower seed oils processed at different temperatures using clays activated with acids of varying concentrations were obtained and used to calculate the changes in turbidity and relative turbidity. As turbidity decreased as the temperature of activation of clay and concentration of acid in the leaching medium increased, the amount of pigment adsorbed, $\mathrm{x}$, increased and the residual relative amount at equilibrium, Xe, decreased for the bleaching of sunflower and cotton seed oils.

The decrease in turbidity with increase in temperature and concentration of acid used, has been interpreted to show that the bleaching capacity of the clays studied increased (Rich, 1964; Topallar, 1998). The increase in bleaching ability was caused by removal of octahedral ions from the clay matrices by the acid and dissociation of water, to produce hydroxyl groups on the clay surface (Jadambaa et al, 2006; Balaras et al, 1999). For sunflower and cotton seed oils, the relative values of quantity of pigment adsorbed, $\mathrm{x}$, mass of clay used, $\mathrm{m}$, and the residual relative quantity in equilibrium, Xe, showed that effective bleaching occurred. The turbidity of bleached cotton-seed oils decreased as the temperature of activation and concentration of the acid in the leaching medium increased. This showed that the amount of pigment adsorbed, $x$, increased and the residual relative amount at equilibrium Xe, decreased for the cotton-seed oils which were bleached. 
The values of turbidity for the bleached cotton and sunflower seed oils processed at different temperatures using clays activated with acids of varying concentrations were obtained and used to calculate the changes in turbidity and relative turbidity. Turbidity decreased as the temperature of activation of clay and concentration of acid in the leaching medium increased, the amount of pigment adsorbed, $\mathrm{x}$, increased and the residual relative amount at equilibrium, $\mathrm{Xe}$, decreased for the bleaching of cotton and sunflower seed oils.

The decrease in turbidity with increase in temperature and concentration of acid used, showed that the bleaching capacity of the clays studied increased (Rich, 1964; Topallar, 1998).

The increase in bleaching ability was caused by removal of octahedral ions from the clay matrices by the acid and dissociation of water, to produce hydroxyl groups on the clay surface (Jadambaa et el, 2006; Balaras et al, 1999). For cotton and sunflower seed oils, the relative values of quantity of pigments or bodies adsorbed, $\mathrm{x}$, mass of clay used, $\mathrm{m}$, and the residual relative quantity in equilibrium, Xe, showed that effective bleaching occurred. The turbidity of bleached cotton and sunflower-seed oils decreased as the temperature of activation and concentration of the acid in the leaching medium increased. This showed that the amount of pigments adsorbed, $x$, increased and the residual relative amount at equilibrium $\mathrm{Xe}$, decreased for the cotton-seed oils which were bleached.

The data in Tables 2 and 3 shows that as the amount of impurities adsorbed increased, the residual relative amount at equilibrium, $\mathrm{Xe}$, decreased for the bleaching of sunflower and cotton seed oils as mass percent of acid used to leach the clay increased. There was also decrease in relative residual amount of impurities in equilibrium with increase in temperature at which the clay was bleached showing the performance of the clay depended on both acid concentration and temperature.

Table 2a and 2b. Representative Langmuir data on cotton oil bleached using clay A

$2 \mathbf{a}$

\begin{tabular}{|l|l|l|l|l|l|l|l|l|}
\hline & \multicolumn{2}{|c|}{ A1 } & \multicolumn{2}{c|}{ A2 } & \multicolumn{2}{c|}{ A3 } & \multicolumn{2}{c|}{ A4 } \\
\hline Temp $/{ }^{\circ} \mathrm{C}$ & $\mathrm{xe}$ & $\mathrm{Xe} /(\mathrm{x} / \mathrm{m})$ & $\mathrm{Xe}$ & $\mathrm{Xe} /(\mathrm{x} / \mathrm{m})$ & $\mathrm{xe}$ & $\mathrm{Xe} /(\mathrm{x} / \mathrm{m})$ & $\mathrm{Xe}$ & $\mathrm{Xe} /(\mathrm{x} / \mathrm{m})$ \\
\hline 40 & 0.93 & 13.286 & 0.89 & 8.091 & 0.85 & 5.667 & 0.79 & 3.762 \\
\hline 50 & 0.9 & 9.000 & 0.86 & 6.143 & 0.80 & 4.000 & 0.77 & 3.348 \\
\hline 60 & 0.86 & 6.143 & 0.83 & 4.882 & 0.77 & 3.348 & 0.74 & 2.846 \\
\hline 70 & 0.81 & 4.263 & 0.75 & 3.000 & 0.72 & 2.571 & 0.70 & 2.333 \\
\hline 80 & 0.78 & 3.545 & 0.73 & 2.704 & 0.70 & 2.333 & 0.68 & 2.125 \\
\hline 90 & 0.72 & 2.571 & 0.70 & 2.333 & 0.68 & 2.125 & 0.66 & 1.941 \\
\hline 100 & 0.71 & 2.448 & 0.69 & 2.226 & 0.67 & 2.094 & 0.65 & 1.857 \\
\hline 110 & 0.71 & 2.448 & 0.69 & 2.226 & 0.67 & 2.094 & 0.67 & 2.094 \\
\hline 120 & 0.72 & 2.571 & 0.70 & 2.333 & 0.68 & 2.125 & 0.68 & 2.125 \\
\hline 130 & 0.72 & 2.571 & 0.70 & 2.333 & 0.68 & 2.125 & .070 & 2.333 \\
\hline
\end{tabular}

2b

\begin{tabular}{|l|l|l|l|l|l|l|l|l|}
\hline & $\mathrm{D} 1$ & & $\mathrm{D} 2$ & & $\mathrm{D} 3$ & & $\mathrm{D} 4$ & \\
\hline $\mathrm{Temp} /{ }^{\circ} \mathrm{C}$ & $\mathrm{xe}$ & $\mathrm{Xe} /(\mathrm{x} / \mathrm{m})$ & $\mathrm{xe}$ & $\mathrm{Xe} /(\mathrm{x} / \mathrm{m})$ & $\mathrm{xe}$ & $\mathrm{Xe} /(\mathrm{x} / \mathrm{m})$ & $\mathrm{xe}$ & $\mathrm{Xe} /(\mathrm{x} / \mathrm{m})$ \\
\hline 40 & 0.88 & 7.33 & 0.84 & 5.25 & 0.78 & 3.545 & 0.71 & 2.448 \\
\hline 50 & 0.85 & 5.667 & 0.81 & 4.263 & 0.73 & 2.704 & 0.68 & 2.125 \\
\hline 60 & 0.81 & 4.263 & 0.78 & 3.545 & 0.70 & 2.333 & 0.66 & 1.941 \\
\hline 70 & 0.76 & 3.167 & 0.70 & 2.333 & 0.65 & 1.857 & 0.61 & 1.564 \\
\hline 80 & 0.73 & 2.704 & 0.68 & 2.125 & 0.63 & 1.703 & 0.59 & 1.439 \\
\hline 90 & 0.67 & 2.030 & 0.65 & 1.857 & 0.61 & 1.564 & 0.56 & 1.273 \\
\hline 100 & 0.66 & 1.941 & 0.64 & 1.778 & 0.60 & 1.500 & 0.55 & 1.222 \\
\hline 110 & 0.66 & 1.941 & 0.64 & 1.778 & 0.60 & 1.500 & 0.58 & 1.381 \\
\hline 120 & 0.68 & 2.125 & 0.66 & 1.941 & 0.61 & 1.564 & 0.58 & 1.381 \\
\hline 130 & 0.68 & 2.125 & 0.64 & 1.778 & 0.61 & 1.564 & 0.60 & 1.500 \\
\hline
\end{tabular}


Table 3a and 3b. Representative Langmuir data on bleached sunflower oil

3a

\begin{tabular}{|l|l|l|l|l|l|l|l|l|}
\hline & $\mathrm{A} 1$ & & $\mathrm{~A} 2$ & & $\mathrm{~A} 3$ & & $\mathrm{~A} 4$ & \\
\hline $\mathrm{Temp} /{ }^{\circ} \mathrm{C}$ & $\mathrm{xe}$ & $\mathrm{Xe} /(\mathrm{x} / \mathrm{m})$ & $\mathrm{xe}$ & $\mathrm{Xe} /(\mathrm{x} / \mathrm{m})$ & $\mathrm{Xe}$ & $\mathrm{Xe} /(\mathrm{x} / \mathrm{m})$ & $\mathrm{xe}$ & $\mathrm{Xe} /(\mathrm{x} / \mathrm{m})$ \\
\hline 40 & 0.93 & 13.286 & 0.89 & 8.091 & 0.85 & 5.667 & 0.79 & 3.762 \\
\hline 50 & 0.90 & 9.00 & 0.86 & 6.143 & 0.80 & 4.000 & 0.77 & 3.348 \\
\hline 60 & 0.86 & 6.143 & 0.83 & 4.882 & 0.77 & 3.348 & 0.74 & 2.846 \\
\hline 70 & 0.81 & 4.263 & 0.75 & 3.000 & 0.72 & 2.571 & 0.70 & 2.333 \\
\hline 80 & 0.78 & 3.545 & 0.73 & 2.703 & 0.70 & 2.333 & 0.68 & 2.125 \\
\hline 90 & 0.72 & 2.571 & 0.70 & 2.333 & 0.68 & 2.125 & 0.66 & 1.941 \\
\hline 100 & 0.71 & 2.448 & 0.69 & 2.226 & 0.67 & 2.030 & 0.65 & 1.857 \\
\hline 110 & 0.71 & 2.448 & 0.69 & 2.226 & 0.68 & 2.125 & 0.67 & 2.030 \\
\hline 120 & 0.72 & 2.571 & 0.70 & 2.333 & 0.68 & 2.125 & 0.68 & 2.125 \\
\hline 130 & 0.72 & 2.571 & 0.70 & 2.333 & 0.68 & 2.125 & 0.70 & 2.333 \\
\hline
\end{tabular}

3b

\begin{tabular}{|l|l|l|l|l|l|l|l|l|}
\hline & $\mathrm{D} 1$ & & $\mathrm{D} 2$ & & $\mathrm{D} 2$ & & $\mathrm{D} 4$ & \\
\hline $\mathrm{Temp} /{ }^{\circ} \mathrm{C}$ & $\mathrm{Xe}$ & $\mathrm{Xe} /(\mathrm{x} / \mathrm{m})$ & $\mathrm{xe}$ & $\mathrm{Xe} /(\mathrm{x} / \mathrm{m})$ & $\mathrm{xe}$ & $\mathrm{Xe} /(\mathrm{x} / \mathrm{m})$ & $\mathrm{xe}$ & $\mathrm{Xe} /(\mathrm{x} / \mathrm{m})$ \\
\hline 40 & 0.92 & 11.500 & 0.87 & 6.692 & 0.82 & 4.556 & 0.74 & 2.846 \\
\hline 50 & 0.89 & 8.091 & 0.84 & 5.250 & 0.77 & 3.348 & 0.72 & 2.571 \\
\hline 60 & 0.85 & 5.667 & 0.81 & 4.263 & 0.74 & 2.846 & 0.69 & 2.226 \\
\hline 70 & 0.80 & 4.000 & 0.73 & 2.704 & 0.69 & 2.226 & 0.64 & 1.778 \\
\hline 80 & 0.77 & 3.348 & 0.71 & 2.448 & 0.67 & 2.030 & 0.63 & 1.703 \\
\hline 90 & 0.71 & 2.448 & 0.68 & 2.125 & 0.65 & 1.857 & 0.61 & 1.564 \\
\hline 100 & 0.70 & 2.333 & 0.67 & 2.030 & 0.64 & 1.778 & 0.60 & 1.667 \\
\hline 110 & 0.70 & 2.333 & 0.67 & 2.030 & 0.64 & 1.778 & 0.62 & 1.632 \\
\hline 120 & 0.71 & 2.448 & 0.68 & 2.125 & 0.65 & 1.857 & 0.63 & 1.703 \\
\hline 130 & 0.72 & 2.571 & 0.69 & 2.226 & 0.66 & 1.941 & 0.65 & 1.857 \\
\hline
\end{tabular}

The least value of $\mathrm{Xe}$ of 0.55 was registered when cotton oil was bleached at $100{ }^{\circ} \mathrm{C}$ with clay $\mathrm{D}$ leached in $25 \%$ sulfuric acid. This indicated that clay gained the highest bleaching efficiency of all the clay studied. The other clays used in the study did not gain high efficiency at bleaching probably due to retention of octahedral cations since these were shown to retard bleaching (Balaras et al, 1999).

The data in Tables 2 and 3 revealed that effective bleaching occurred in the ranges of temperatures between 40 and $90^{\circ} \mathrm{C}$ because both $\mathrm{Xe}$ and $\mathrm{x} / \mathrm{m}$ values decreased within this temperature range for all clays studied. However, the decrease in Xe and Xe / $(\mathrm{x} / \mathrm{m})$ was most rapid for the clay D from Chelel, leached in $25 \%$ acid mixture because the original clay had the highest nontronite content among the clays studied. So it gained the highest bleaching capability (Christidis and Kossairi, 2003).

An isotherm expresses the relationship between the partial pressure of adsorbate gas, or solute concentration in solution, and the surface coverage of the adsorbent at a constant temperature (Gregg and Sing, 1997). The Langmuir isotherm has been used to describe the adsorption of pigments or color bodies and other minor oil solutes during oil bleaching process. The Langmuir isotherms in Figures $1 \mathrm{a}$ to $1 \mathrm{~d}$ and $2 \mathrm{a}$ to $2 \mathrm{~d}$ have been developed using variation of turbidity vegetable oil caused by bleaching with clays at different temperatures of activation. The representative Figures 1a to 1d for cotton oils and $2 \mathrm{a}$ to $2 \mathrm{~d}$ for sunflower seed oils both have positive slopes showing that clays were helpful in removing particles which contaminate oils.

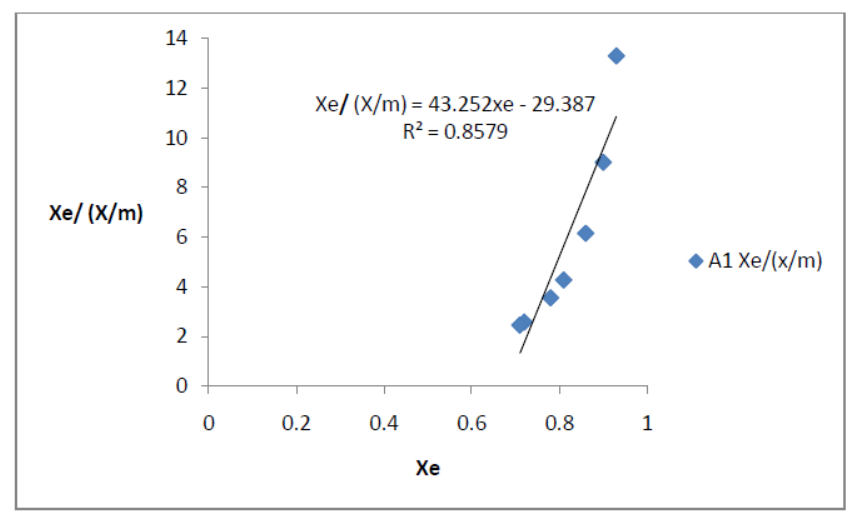

$1 a$

International Journal of Advanced Research in Chemical Science (IJARCS) 


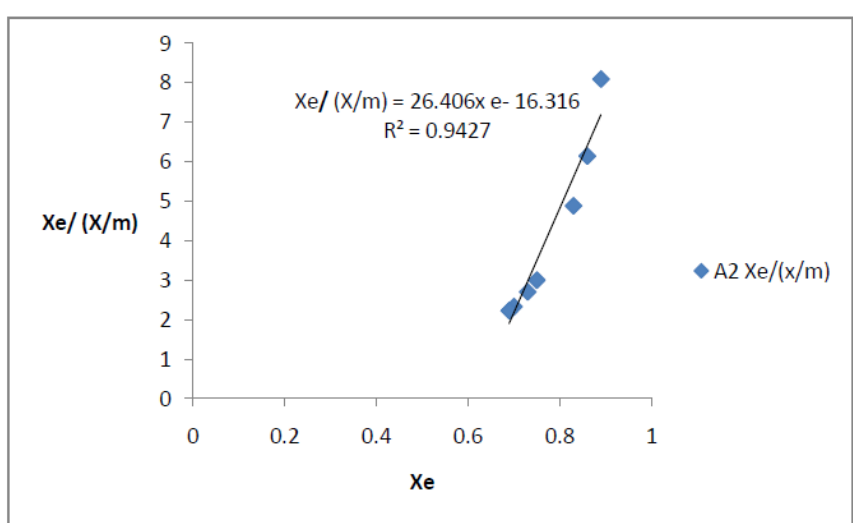

1b

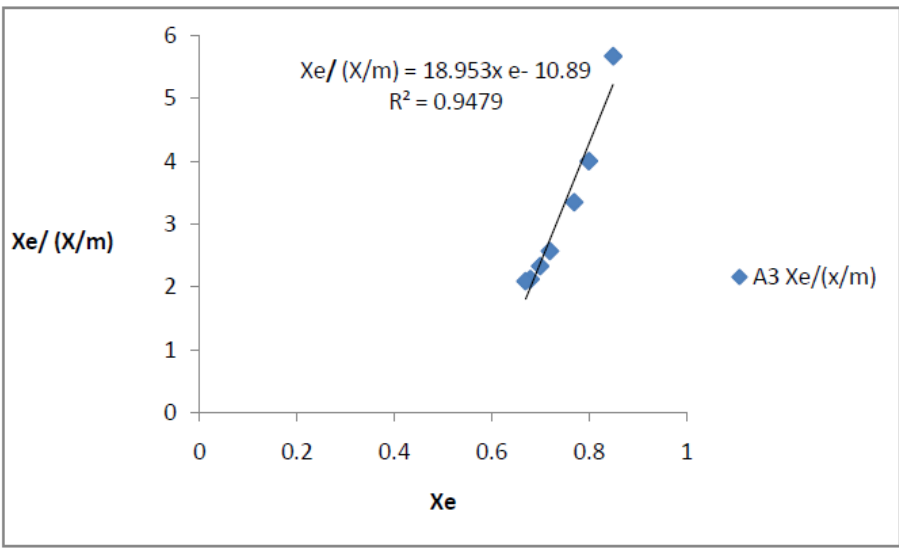

$1 c$

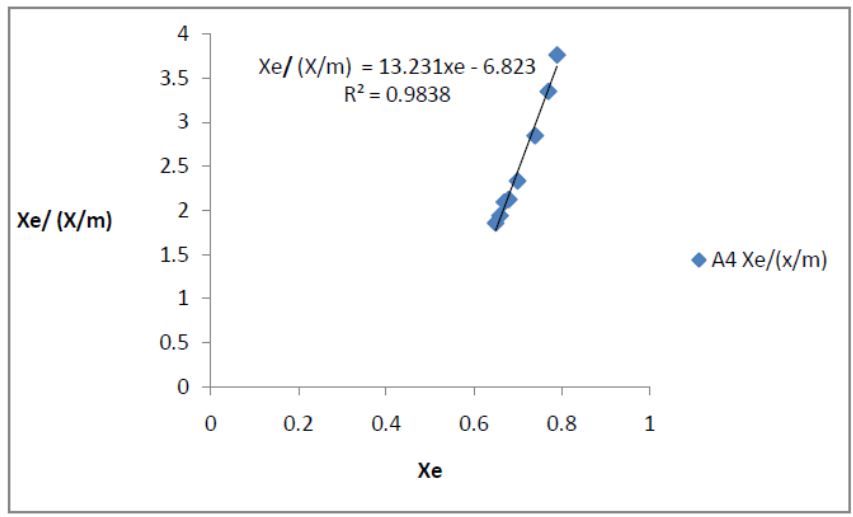

1d

Figures 1a to 1d. Representative Langmuir isotherms for bleaching of cotton oils

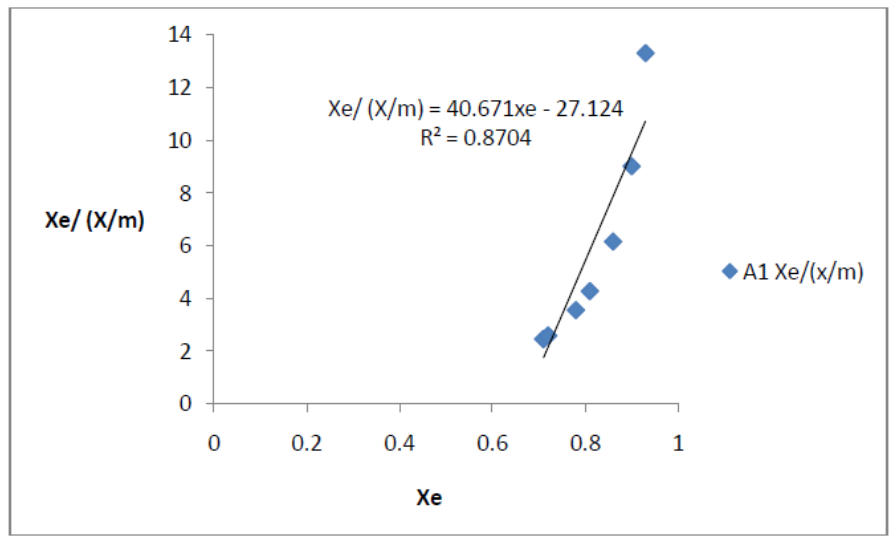

$\mathbf{2 a}$ 


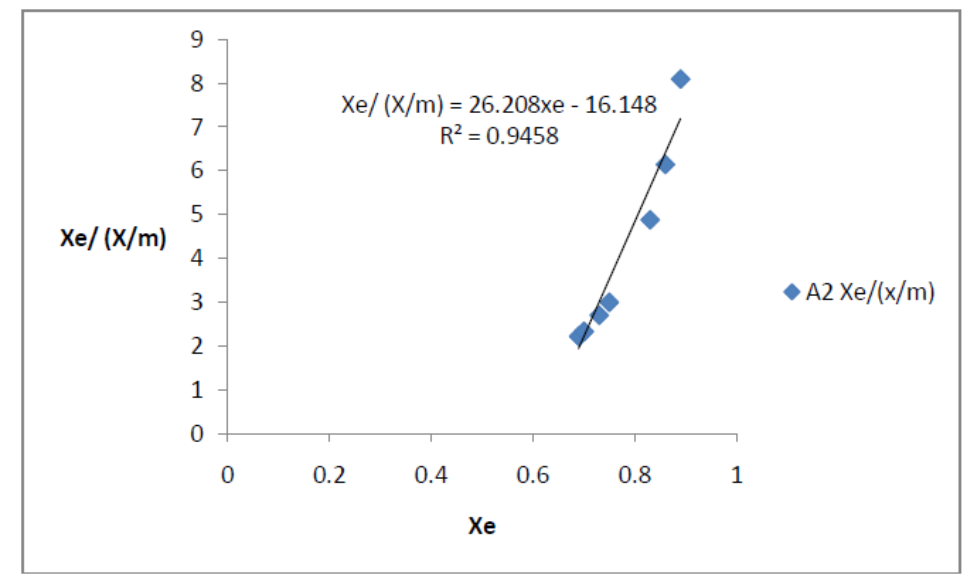

2b

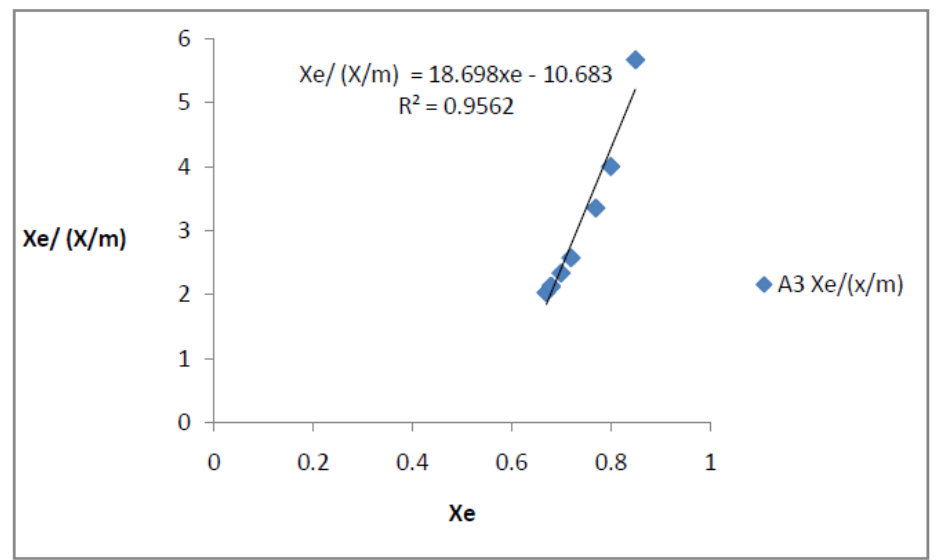

2c

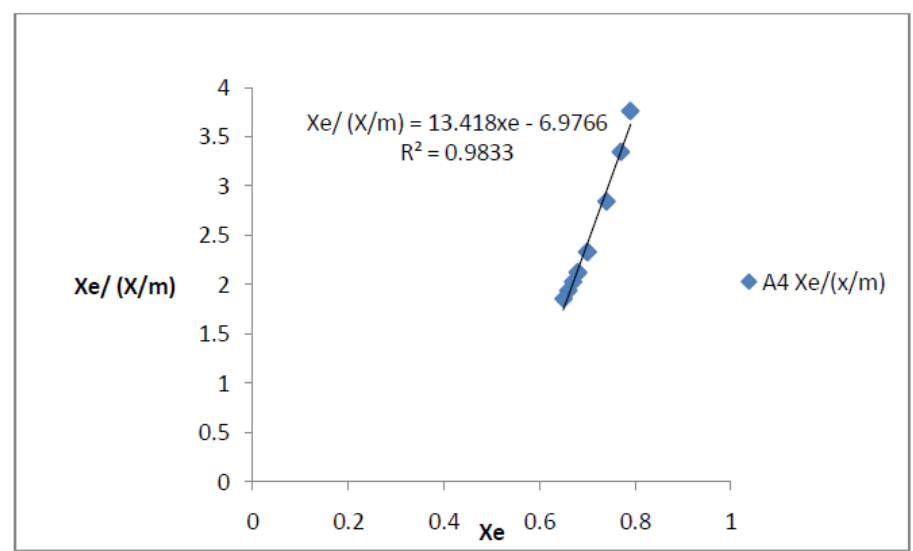

2d

Figures 2a to 2d. Representative Langmuir isotherms for bleaching of sunflower oils

The slopes of the plots given in Figures 1a-1d and 2a-2d increased with increase in temperature used to activate the clays in the range of 40 to $90{ }^{\circ} \mathrm{C}$, showing that effective bleaching occurred within this temperature range (Yuksel, 2003). The representative Langmuir isotherms in Figures 1a-1d and 2a-2d show that acid-activated clays bleached better when treated with $25 \%$ acid and activated at temperature near $90^{\circ} \mathrm{C}$ (Siddiqui, 1989). Each plot depicts the decrease in values of Langmuir constants $a$ and $b$ as the temperature increased from 40 to $90^{\circ} \mathrm{C}$. The linearity of these Langmuir isotherms has been inferred to show that the effectiveness of the adsorptive process for impurities on the clays increased with increase in temperature used to activate the clays.

As seen from the Figures 1a-1d and 2a-2d linear graphs resulted showing that Langmuir adsorption isotherms were obeyed when acid-leached clays adsorbed impurities from sunflower and cotton-seed oils. The extent of adsorption increased with temperature and clays leached with $25 \%$ acid showed highest adsorptive tendencies. The coefficients of linearity, expressed as $\mathrm{R}^{2}$ values for clay $\mathrm{A}$ 
increased from as low as $0.8579 \pm 0.017$ for $\mathrm{A} 1$ to as high as $0.9838 \pm 0.017$ for $\mathrm{A} 4$. This revealed the adsorptive capacity of clays was strongest when the clay had been leached in $25 \%$ sulfuric acid. This indicated that the capacity to bind impurities and suspended solids was only fair because of steric interferences between the adsorbed and free impurities present in vegetable oils being bleached was low (Travis and Etnier, 1981; Olsen and Watanabe; 1957).

The $\mathrm{R}^{2}$ values for clay $\mathrm{D}$ increased from as low as $0.9332 \pm 0.017$ for $\mathrm{D} 1$ to as high as $0.9874 \pm 0.017$ for $\mathrm{D} 4$. This revealed the adsorptive capacity of clays was strongest when the clay had been leached in $25 \%$ sulfuric acid. So the capacity of leached clay to bind impurities and suspended solids was high because of steric interferences between the adsorbed and free impurities present in vegetable oils did not set in during the bleaching process when these clays were used. It was reported that high degree of linearity was observed when the soil had not reached its saturation point with the adsorbate because of presence of many adsorptive sites (Hundal, 1988). So linearity would be extended to higher concentration of impurity in oils. The values of Langmuir constants $a$ and $b$ were calculated and listed for every clay with the linearized isotherm as shown below.

Langmuir isotherms for cotton oils were;

$\mathrm{Xe} /(\mathrm{X} / \mathrm{m})=43.252 \mathrm{xe}-29.387, \mathrm{R}^{2}=0.8579, \mathrm{a}=0.02312, \mathrm{~b}=0.6794$ for $\mathrm{A} 1$.

$\mathrm{Xe} /(\mathrm{X} / \mathrm{m})=26.406 \mathrm{xe}-16.316, \mathrm{R}^{2}=0.9427, \mathrm{a}=0.0379, \mathrm{~b}=0.61789$ for $\mathrm{A} 2$.

$\mathrm{Xe} /(\mathrm{X} / \mathrm{m})=18.953 \mathrm{xe}-10.89, \mathrm{R}^{2}=0.9479, \mathrm{a}=0.05276, \mathrm{~b}=0.57458$ for $\mathrm{A} 3$.

$\mathrm{Xe} /(\mathrm{X} / \mathrm{m})=13.231 \mathrm{xe}-6.823, \mathrm{R}^{2}=0.9838, \mathrm{a}=0.0756, \mathrm{~b}=0.5157$ for $\mathrm{A} 4$.

$\mathrm{Xe} /(\mathrm{X} / \mathrm{m})=37.374 \mathrm{xe}-24.888, \mathrm{R}^{2}=0.8597, \mathrm{a}=0.0268, \mathrm{~b}=0.6659$ for $\mathrm{B} 1$.

$\mathrm{Xe} /(\mathrm{X} / \mathrm{m})=23.578 \mathrm{xe}-14.078, \mathrm{R}^{2}=0.9439, \mathrm{a}=0.0424, \mathrm{~b}=0.5971$ for $\mathrm{B} 2$.

$\mathrm{Xe} /(\mathrm{X} / \mathrm{m})=14.078 \mathrm{xe}-7.3804, \mathrm{R}^{2}=0.9667, \mathrm{a}=0.0710, \mathrm{~b}=0.5243$ for $\mathrm{B} 3$.

$\mathrm{Xe} /(\mathrm{X} / \mathrm{m})=8.6984 \mathrm{xe}-3.7321, \mathrm{R}^{2}=0.9855, \mathrm{a}=0.1150, \mathrm{~b}=0.4291$ for $\mathrm{B} 4$.

$\mathrm{Xe} /(\mathrm{X} / \mathrm{m})=31.879 \mathrm{xe}-20.421, \mathrm{R}^{2}=0.9077, \mathrm{a}=0.0314, \mathrm{~b}=0.6406$ for $\mathrm{C} 1$.

$\mathrm{Xe} /(\mathrm{X} / \mathrm{m})=18.676 \mathrm{xe}-10.685, \mathrm{R}^{2}=0.9659, \mathrm{a}=0.0535, \mathrm{~b}=0.5721$ for $\mathrm{C} 2$.

$\mathrm{Xe} /(\mathrm{X} / \mathrm{m})=11.735 \mathrm{xe}-5.7153, \mathrm{R}^{2}=0.9703, \mathrm{a}=0.0852, \mathrm{~b}=0.4870$ for $\mathrm{C} 3$.

$\mathrm{Xe} /(\mathrm{X} / \mathrm{m})=7.9567 \mathrm{xe}-3.2497, \mathrm{R}^{2}=0.9832, \mathrm{a}=0.1257, \mathrm{~b}=0.4084$ for $\mathrm{C} 4$.

$\mathrm{Xe} /(\mathrm{X} / \mathrm{m})=21.679 \mathrm{xe}-12.67, \mathrm{R}^{2}=0.9332, \mathrm{a}=0.0461, \mathrm{~b}=0.5844$ for $\mathrm{D} 1$.

$\mathrm{Xe} /(\mathrm{X} / \mathrm{m})=15.926 \mathrm{xe}-8.5472, \mathrm{R}^{2}=0.9681, \mathrm{a}=0.0628, \mathrm{~b}=0.5367$ for $\mathrm{D} 2$.

$\mathrm{Xe} /(\mathrm{X} / \mathrm{m})=10.634 \mathrm{xe}-4.9502, \mathrm{R}^{2}=0.9753, \mathrm{a}=0.0940, \mathrm{~b}=0.4655$ for $\mathrm{D} 3$.

$\mathrm{Xe} /(\mathrm{X} / \mathrm{m})=7.5482 \mathrm{xe}-2.9921, \mathrm{R}^{2}=0.9874, \mathrm{a}=0.1325, \mathrm{~b}=0.3964$ for $\mathrm{D} 4$.

Linearized Langmuir isotherms developed while bleaching sunflower oil are as shown below;

$\mathrm{Xe} /(\mathrm{X} / \mathrm{m})=40.671 \mathrm{xe}-27.124, \mathrm{R}^{2}=0.8704, \mathrm{a}=0.0246, \mathrm{~b}=0.6669$ for $\mathrm{A} 1$.

$\mathrm{Xe} /(\mathrm{X} / \mathrm{m})=26.208 \mathrm{xe}-16.148, \mathrm{R}^{2}=0.9458, \mathrm{a}=0.0382, \mathrm{~b}=0.6161$ for $\mathrm{A} 2$.

$\mathrm{Xe} /(\mathrm{X} / \mathrm{m})=18.698 \mathrm{x}-10.683, \mathrm{R}^{2}=0.9562, \mathrm{a}=0.0535, \mathrm{~b}=0.57133$ for $\mathrm{A} 3$.

$\mathrm{Xe} /(\mathrm{X} / \mathrm{m})=13.418 \mathrm{xe}-6.9766, \mathrm{R}^{2}=0.9833, \mathrm{a}=0.0745, \mathrm{~b}=0.5199$ for $\mathrm{A} 4$.

$\mathrm{Xe} /(\mathrm{X} / \mathrm{m})=41.306 \mathrm{xe}-27.685, \mathrm{R}^{2}=0.8633, \mathrm{a}=0.02421, \mathrm{~b}=0.0209$ for $\mathrm{B} 1$.

$\mathrm{Xe} /(\mathrm{X} / \mathrm{m})=23.637 \mathrm{xe}-14.224, \mathrm{R}^{2}=0.949, \mathrm{a}=0.0423, \mathrm{~b}=0.6018$ for $\mathrm{B} 2$.

$\mathrm{Xe} /(\mathrm{X} / \mathrm{m})=15.631 \mathrm{xe}-8.4449, \mathrm{R}^{2}=0.9603, \mathrm{a}=0.0640, \mathrm{~b}=0.5403$ for $\mathrm{B} 3$.

$\mathrm{Xe} /(\mathrm{X} / \mathrm{m})=10.587 \mathrm{xe}-4.987, \mathrm{R}^{2}=0.9846, \mathrm{a}=0.0945, \mathrm{~b}=0.4710$ for $\mathrm{B} 4$.

$\mathrm{Xe} /(\mathrm{X} / \mathrm{m})=31.721 \mathrm{xe}-20.316, \mathrm{R}^{2}=0.9048, \mathrm{a}=0.0315, \mathrm{~b}=0.6405$ for $\mathrm{C} 1$.

$\mathrm{Xe} /(\mathrm{X} / \mathrm{m})=22.246 \mathrm{xe}-13.248, \mathrm{R}^{2}=0.9625, \mathrm{a}=0.04495, \mathrm{~b}=0.5955$ for $\mathrm{C} 2$.

$\mathrm{Xe} /(\mathrm{X} / \mathrm{m})=15.585 \mathrm{xe}-8.4111, \mathrm{R}^{2}=0.9626, \mathrm{a}=0.0642, \mathrm{~b}=0.5397$ for $\mathrm{C} 3$.

$\mathrm{Xe} /(\mathrm{X} / \mathrm{m})=11.61 \mathrm{xe}-5.7023, \mathrm{R}^{2}=0.9854, \mathrm{a}=0.0861, \mathrm{~b}=0.4912$ for $\mathrm{C} 4$.

$\mathrm{Xe} /(\mathrm{X} / \mathrm{m})=27.16 \mathrm{xe}-16.998, \mathrm{R}^{2}=0.9247, \mathrm{a}=0.0368, \mathrm{~b}=0.6258$ for $\mathrm{D} 1$.

$\mathrm{Xe} /(\mathrm{X} / \mathrm{m})=21.303 \mathrm{xe}-12.481, \mathrm{R}^{2}=0.9542, \mathrm{a}=0.0469, \mathrm{~b}=0.5859$ for $\mathrm{D} 2$.

$\mathrm{Xe} /(\mathrm{X} / \mathrm{m})=14.322 \mathrm{xe}-7.5027, \mathrm{R}^{2}=0.9652, \mathrm{a}=0.0698, \mathrm{~b}=0.5239$ for $\mathrm{D} 3$.

$\mathrm{Xe} /(\mathrm{X} / \mathrm{m})=9.0219 \mathrm{xe}-3.9223, \mathrm{R}^{2}=0.9663, \mathrm{a}=0.1108, \mathrm{~b}=0.4348$ for $\mathrm{D} 4$. 
The values of the Langmuir constants $a$ and $b$ decreased with increase in concentrations of the acid used to leach every clay studied because leaching increased the number of adsorption sites per unit mass of clay. The values of $a$ and $b$ decreased also with increase in the temperature at which the clay was thermally activated. This was due to the heat of activation of the clay leads to increase in number of adsorption sites per gram of clay matrix. However, the decrease in values of constants $a$ and $b$ for clay D were particularly higher than those for any other clay studied, as this clay had a much higher smectite content than others used in this study. So its activated forms had higher numbers of adsorptive sites for colored impurities and suspended solids in the raw cotton and sunflower seed oils.

The linearity of the isotherms was a function of impurity concentration, availability of surface adsorption sites and interactions between the adsorbed impurities and impurities still remaining unadsorbed in the oil being bleached (Hundal, 1988). As clays B, C and D showed greater degree of linearity of isotherms than clay $\mathrm{A}$, it has been concluded that acid-leached smectites obey Langmuir adsorption more closely (Alemdaroglu et al, 2003).

The tests conducted, where bleaching was optimized at different temperatures and concentrations acid to activate clays, the slopes for the Langmuir isotherms were positive showing that bleaching capacity and surface area increased with increase in both temperature and concentration of acid used (Alemdaroglu et al, 2003). So linearity would be extended to higher concentration of impurity in oils. As long as the clay material did not easily reach saturation with the adsorbed impurities, the Langmuir isotherms obtained were highly linear. The degree of linearity reduced as the saturation point for the clay was approached (Vandenbruwane et al, 2007).

Clay materials with fewer surface sites where impurities adsorb easily deviate from linearity of Langmuir isotherms. Similarly, clays whose surface sites have non uniform enthalpies of adsorption deviate from linearity, as the sites compete for the impurities in the oils being bleached (Travis and Etnier, 1981; Fried and Shapiro, 1956). The nature of first class Langmuir isotherms are determined by sorption characteristics of soil minerals (Kothawala et al, 2008). Nitrogen adsorption data for the characterization of nanoporous silicas were observed to give excellent linear Langmuir isotherms in the low pressure range and deviated at higher relative pressure (Jaroniec and Kruk, 1999; Allen et al, 1998). The deviation from linearity of Langmuir isotherms occurs in three regions, which is attributed to existence of surface sites having multiple adsorption free energies (Srinivasan and Fogler, 1990). The adsorption of impurities in oils may be governed by impurity-oil and impurity-clay surface interactions (Travis and Etnier, 1981). Steric interferences hamper adsorption.

The increased linearity as temperature increased for all the clays tested confirmed that the bleaching activity or decolorizing power of the clay matrices increased with increase in temperature up to a maximum at range between 90 and $110{ }^{\circ} \mathrm{C}$. When adsorption conforms to the Langmuir equation it can not be used as absolute proof of the mechanism (Gregg and Sing, 1997). If bleaching is carried out at temperature in range between 90 and $110{ }^{\circ} \mathrm{C}$ oils with good characteristics are obtained, indicating that at this temperature the crystal structure of the clay materials are not greatly changed as crystal water would not have been lost (Dandy, 1968). This evidence is also used to indicate that the water or/and hydroxyl groups in the clay play a major role in the bleaching of vegetable oils (Rich, 1964).

The gradients of the graphs in Figures $1 \mathrm{a}-1 \mathrm{~d}$ and $2 \mathrm{a}-2 \mathrm{~d}$ increased positively with increase in concentration of the acid used to leach the clay because acid-activation of the clay greatly enhanced the bleaching capacity of the clay. Acid-leaching removed octahedral ions like sodium, magnesium, calcium and potassium ions from the clay matrix which retard bleaching (Balaras et al, 1999). Removal of octahedral ions left a silica skeleton with enhanced adsorptive properties (Boyd, 1988; Hassan, 2006; Madejova, 2007). Langmuir constants decreased with increasing temperature for all adsorbent systems used. This indicated increasing availability of adsorption sites with elevated temperatures because all sites were not energetically equal (Boki et al, 1992). Langmuir constants decreased with increasing concentration of acid used to leach the clays as well as the temperature used to activate the clays. This indicated that acid-leaching and heating up to temperatures below $90^{\circ} \mathrm{C}$ increased availability of adsorption sites because all sites were not energetically equal (Boki et al, 1992). Bleaching involves adsorption of coloring matter and other impurities on bleaching earths. Therefore a comparison, in form of adsorption isotherms between the color and turbidity of bleached and unbleached oils is of great importance. The isotherms portray what takes place in the entire bleaching process at various temperatures. Freundlich and Langmuir isotherms were presented and shown to elucidate adsorption characteristics of pigments in oils on clays and sepiolites (Boki et al, 
1992). The color and turbidity of bleached and unbleached sunflower-seed and cotton-seed oils have been used to study the nature and extent of adsorption of the impurities in crude oils on clay materials (Mbah, 2005; Topallar, 1998). The decrease in turbidity of cotton and sunflower seed oils on being bleached has been explained in a similar way to what Hui (1996) noted when they separately observed the 5-20\% reduction in the red color of soybean, canola and palm oils occurred during the bleaching with acid activated bleaching earths. They noted that a breakdown occurs in chlorophyll and carotene concentrations for which it was concluded that the increase in adsorption activity of clays after acid treatment is due to the weakness of the $\mathrm{Si}-\mathrm{O}$ bonds in the clay structure (Hui, 1996).

The representative data in Tables 2 and 3 , have been used to calculate the logarithmic relation (Achife, 1989). The data in Tables 4 and 5 give the values of $\log (\mathrm{x} / \mathrm{m})$ and $\log \mathrm{Xe}$ for clays $\mathrm{A}, \mathrm{B}, \mathrm{C}$ and $\mathrm{D}$ used in the study. The representative data in Tables 4 and 5 showed decrease in the relative residual quantities of impurities in oils within the temperature range between 40 and $90^{\circ} \mathrm{C}$, it can be inferred that effective bleaching takes place in these temperature range. Bleaching is accompanied by enthalpies of adsorption due to decrease in relative residual impurities with increase in temperature and concentration of acid used to leach the clays. The values in Tables 4 and 5 showed that the extent of adsorption of impurities from vegetable oils increased as temperature of clay activation increased, further indicating Freundlich adsorption isotherms can be developed for the bleaching of vegetable oils using clay adsorptive materials. The method used in this study to predict adsorption of impurities in vegetable oils was successfully employed in bleaching hazelnut oil, to investigate the applicability of the Langmuir and Freundlich equations and to elucidate the adsorption characteristics of oil on bentonite EY-09 (Bensan Co. Ltd., Edirne, Turkey) using adsorption isotherms (Yuksel, 2003).

Tables 4a and 4b. Representative Freundlich data for cotton oil

$4 \mathbf{a}$

\begin{tabular}{|l|l|l|l|l|l|l|l|l|}
\hline & \multicolumn{3}{|c|}{ A1 } & \multicolumn{2}{c|}{ A2 } & \multicolumn{2}{c|}{ A3 } & \multicolumn{2}{c|}{ A4 } \\
\hline & $\operatorname{logxe}$ & $\operatorname{logxe} /(\mathrm{x} / \mathrm{m})$ & $\log \mathrm{Xe}$ & $\operatorname{logxe} /(\mathrm{x} / \mathrm{m})$ & $\operatorname{logxe}$ & $\log \mathrm{xe} /(\mathrm{x} / \mathrm{m})$ & $\operatorname{logXe}$ & $\operatorname{logxe} /(\mathrm{x} / \mathrm{m})$ \\
\hline 40 & -0.032 & -1.155 & -0.051 & -0.959 & -0.0706 & -0.8239 & -0.1024 & -0.6778 \\
\hline 50 & -0.046 & -1.000 & -0.0655 & -0.8539 & -0.0969 & -0.6990 & -0.1135 & -0.6383 \\
\hline 60 & -0.066 & -0.854 & -0.0809 & -0.7696 & -0.1135 & -0.6383 & -0.1308 & -0.5850 \\
\hline 70 & -0.092 & -0.721 & -0.1249 & -0.6021 & -0.1427 & -0.5528 & -0.1549 & -0.5229 \\
\hline 80 & -0.108 & -0.658 & -0.1367 & -0.5686 & -0.1549 & -0.5229 & -0.1675 & -0.4949 \\
\hline 90 & -0.143 & -0.553 & -0.1549 & -0.5229 & -0.1675 & -0.4949 & -0.1805 & -0.4685 \\
\hline 100 & -0.149 & -0.538 & -0.1612 & -0.5086 & -0.1739 & -0.4815 & -0.1871 & -0.4559 \\
\hline 110 & -0.149 & -0.538 & -0.1612 & -0.5086 & -0.1739 & -0.4815 & -0.1739 & -0.4815 \\
\hline 120 & -0.143 & -0.553 & -0.1549 & -0.5229 & -0.1675 & -0.4949 & -0.1675 & -0.4949 \\
\hline 130 & -0.143 & -0.553 & -0.1549 & -0.5229 & -0.1675 & -0.4949 & -0.1549 & -0.5229 \\
\hline
\end{tabular}

$4 \mathbf{b}$

\begin{tabular}{|l|l|l|l|l|l|l|l|l|}
\hline & \multicolumn{2}{|c|}{$\mathrm{D} 1$} & \multicolumn{2}{c|}{$\mathrm{D} 2$} & \multicolumn{2}{c|}{$\mathrm{D} 3$} & \multicolumn{2}{c|}{$\mathrm{D} 4$} \\
\hline & $\mathrm{xe}$ & $\log (\mathrm{x} / \mathrm{m})$ & $\mathrm{xe}$ & $\log (\mathrm{x} / \mathrm{m})$ & $\log \mathrm{xe}$ & $\log (\mathrm{x} / \mathrm{m})$ & $\operatorname{logxe}$ & $\log (\mathrm{x} / \mathrm{m})$ \\
\hline 40 & -0.0555 & -0.9208 & -0.0757 & -0.7959 & -0.1079 & -0.6576 & -0.1487 & -0.5376 \\
\hline 50 & -0.0706 & -0.8239 & -0.0915 & -0.7212 & -0.1367 & -0.5686 & -0.1675 & -0.4949 \\
\hline 60 & -0.0915 & -0.7212 & -0.1079 & -0.6576 & -0.1549 & -0.5229 & -0.1805 & -0.4685 \\
\hline 70 & -0.1192 & -0.6198 & -0.1549 & -0.5229 & -0.1871 & -0.4559 & -0.2147 & -0.4089 \\
\hline 80 & -0.1367 & -0.5686 & -0.1675 & -0.4949 & -0.2007 & -0.4318 & -0.2291 & -0.3872 \\
\hline 90 & -0.1739 & -0.4815 & -0.1871 & -0.4559 & -0.2147 & -0.4089 & -0.2518 & -0.3565 \\
\hline 100 & -0.1805 & -0.4685 & -0.1938 & -0.4437 & -0.2218 & -0.3979 & -0.2596 & -0.3468 \\
\hline 110 & -0.1805 & -0.4685 & -0.1938 & -0.4437 & -0.2218 & -0.3979 & -0.2366 & -0.3768 \\
\hline 120 & -0.1675 & -0.4949 & -0.1805 & -0.4685 & -0.2147 & -0.4089 & -0.2366 & -0.3768 \\
\hline 130 & -0.1675 & -0.4949 & -0.1805 & -0.4685 & -0.2147 & -0.4089 & -0.2218 & -0.3979 \\
\hline
\end{tabular}

Tables 5 a and 5b. Representative Freundlich data for sunflower oils

5a

\begin{tabular}{|l|l|l|l|l|l|l|l|l|}
\hline & A1 & & A2 & & A3 & & A4 & \\
\hline & $\log \mathrm{xe}$ & $\log (\mathrm{x} / \mathrm{m})$ & $\log \mathrm{x} e$ & $\log (\mathrm{x} / \mathrm{m})$ & $\log \mathrm{Xe}$ & $\log (\mathrm{x} / \mathrm{m})$ & $\log \mathrm{xe}$ & $\log (\mathrm{x} / \mathrm{m})$ \\
\hline 40 & -0.0315 & -1.1549 & -0.0506 & -0.9586 & -0.0706 & -0.8239 & -0.1024 & -0.6778 \\
\hline 50 & -0.0458 & -1.000 & -0.0655 & -0.8539 & -0.0970 & -0.6990 & -0.1135 & -0.638 \\
\hline 60 & -0.0655 & -0.8539 & -0.0809 & -0.7696 & -0.1135 & -0.6383 & -0.1308 & -0.5850 \\
\hline
\end{tabular}

International Journal of Advanced Research in Chemical Science (IJARCS)

Page | 50 
How Variation of Turbidity of Bleached Oils Characterizes Purity Oil and Bleaching Processes

\begin{tabular}{|l|l|l|l|l|l|l|l|l|}
\hline 70 & -0.0915 & -0.7212 & -0.1249 & -0.6021 & -0.1427 & -0.5528 & -0.1549 & -0.5229 \\
\hline 80 & -0.1079 & -0.6576 & -0.1367 & -0.5686 & -0.1549 & -0.5229 & -0.1675 & -0.4949 \\
\hline 90 & -0.1427 & -0.5528 & -0.1549 & -0.5229 & -0.1675 & -0.4949 & -0.1805 & -0.4685 \\
\hline 100 & -0.1487 & -0.5376 & -0.1612 & -0.5086 & -0.1739 & -0.4815 & -0.1871 & -0.4559 \\
\hline 110 & -0.1487 & -0.5376 & -0.1612 & -0.5086 & -0.1675 & -0.4815 & -0.1739 & -0.4815 \\
\hline 120 & -0.1427 & -0.5528 & -0.1549 & -0.5229 & -0.1675 & -0.4949 & -0.1675 & -0.4949 \\
\hline 130 & -0.1427 & -0.5528 & -0.1549 & -0.5229 & -0.1675 & -0.4949 & -0.1549 & -0.5229 \\
\hline
\end{tabular}

$\mathbf{5 b}$

\begin{tabular}{|l|l|l|l|l|l|l|l|l|}
\hline & \multicolumn{2}{|c|}{$\mathrm{D} 1$} & \multicolumn{2}{c|}{$\mathrm{D} 2$} & \multicolumn{2}{c|}{$\mathrm{D} 3$} & \multicolumn{2}{c|}{$\mathrm{D} 4$} \\
\hline & $\mathrm{Log} \mathrm{Xe}$ & $\log (\mathrm{x} / \mathrm{m})$ & $\operatorname{logxe}$ & $\log (\mathrm{x} / \mathrm{m})$ & $\operatorname{logxe}$ & $\log (\mathrm{x} / \mathrm{m})$ & $\operatorname{logxe}$ & $\log (\mathrm{x} / \mathrm{m})$ \\
\hline 40 & -0.036 & -1.097 & -0.0605 & -0.8861 & -0.0862 & -0.7447 & -0.1308 & -0.5850 \\
\hline 50 & -0.051 & -0.959 & -0.0757 & -0.7959 & -0.1135 & -0.6383 & -0.1427 & -0.5528 \\
\hline 60 & -0.071 & -0.824 & -0.0915 & -0.7212 & -0.1308 & -0.5850 & -0.1612 & -0.5086 \\
\hline 70 & -0.097 & -0.699 & -0.1367 & -0.5686 & -0.1612 & -0.5086 & -0.1938 & -0.4437 \\
\hline 80 & -0.114 & -0.638 & -0.1487 & -0.5376 & -0.1739 & -0.4815 & -0.2007 & -0.4318 \\
\hline 90 & -0.149 & -0.538 & -0.1675 & -0.4949 & -0.1871 & -0.4559 & -0.2147 & -0.4089 \\
\hline 100 & -0.155 & -0.523 & -0.1739 & -0.4815 & -0.1938 & -0.4437 & -0.2218 & -0.3979 \\
\hline 110 & -0.155 & -0.523 & -0.1739 & -0.4815 & -0.1938 & -0.4437 & -0.2076 & -0.4202 \\
\hline 120 & -0.149 & -0.538 & -0.1675 & -0.4949 & -0.1871 & -0.4559 & -0.2007 & -0.4318 \\
\hline 130 & -0.143 & -0.553 & -0.1612 & -0.5086 & -0.1805 & -0.4685 & -0.1871 & -0.4949 \\
\hline
\end{tabular}

The representative data in Tables 4 and 5 was plotted to yield Freundlich isotherms shown in Figures $3 a-3 d, 4 a-4 d, 5 a-5 d$ and $6 a-6 d$.

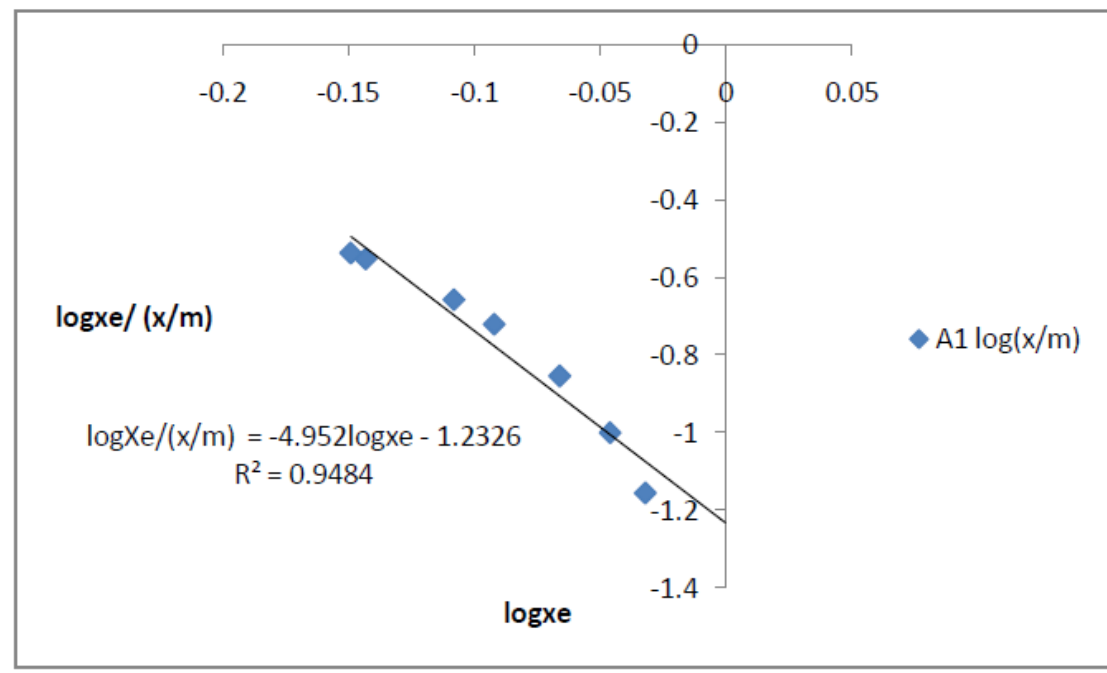

3a

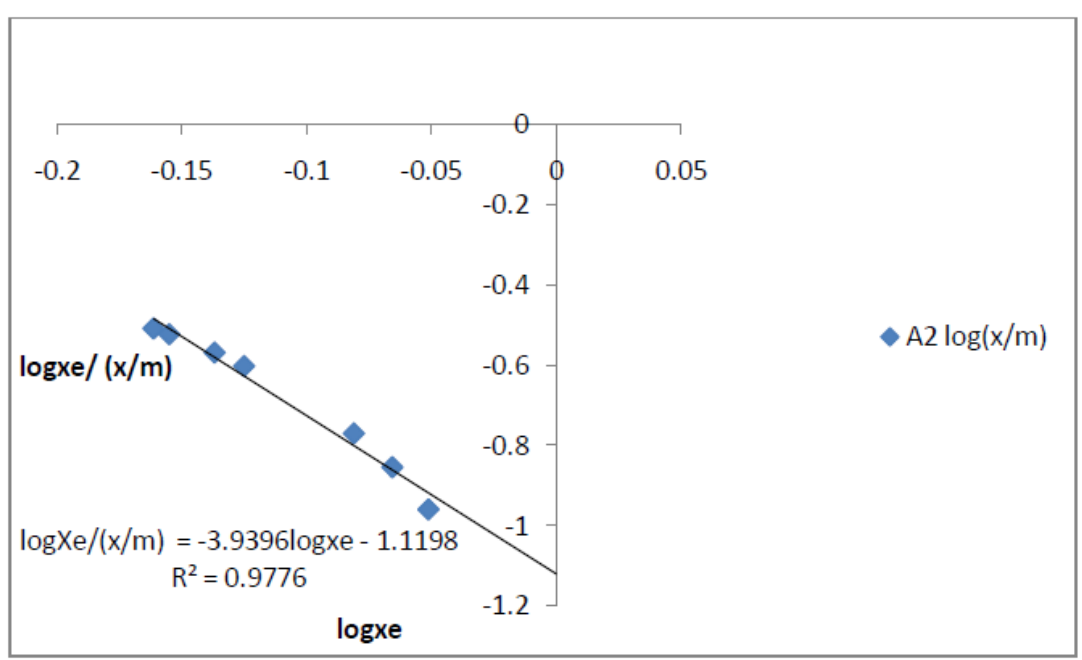

3b 


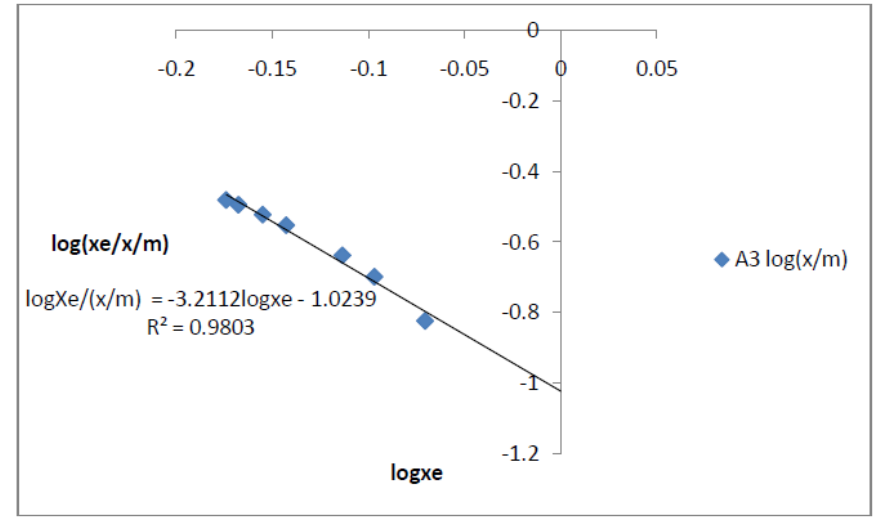

3c

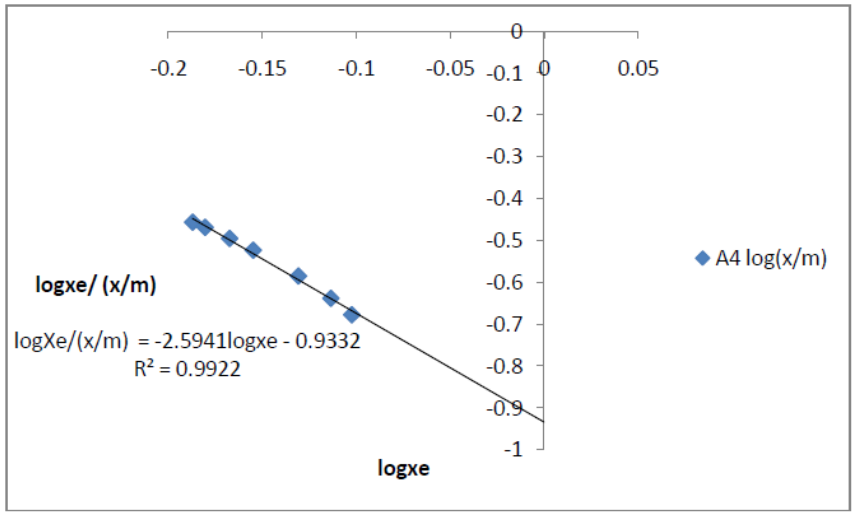

3d

Figures 3a-3d. Freundlich isotherm for cotton oil bleached using clayA

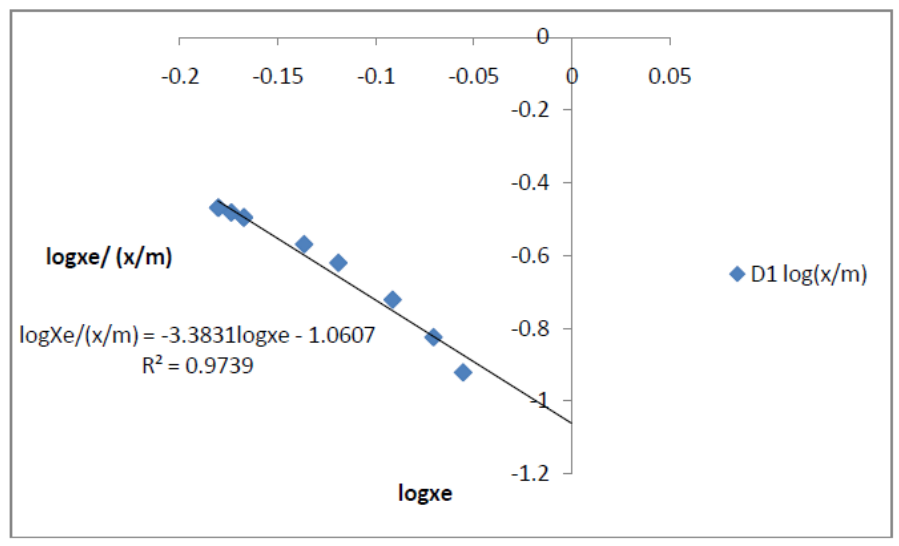

$4 a$

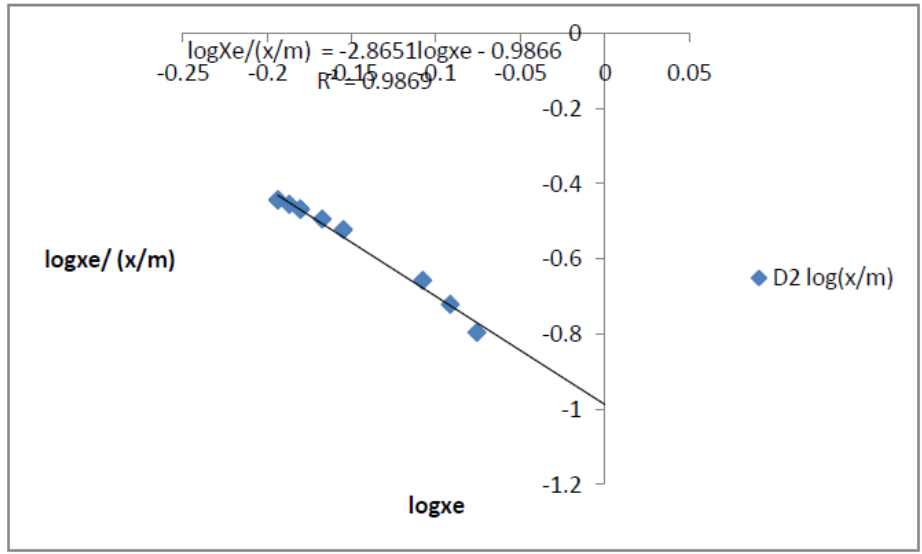

$4 b$ 


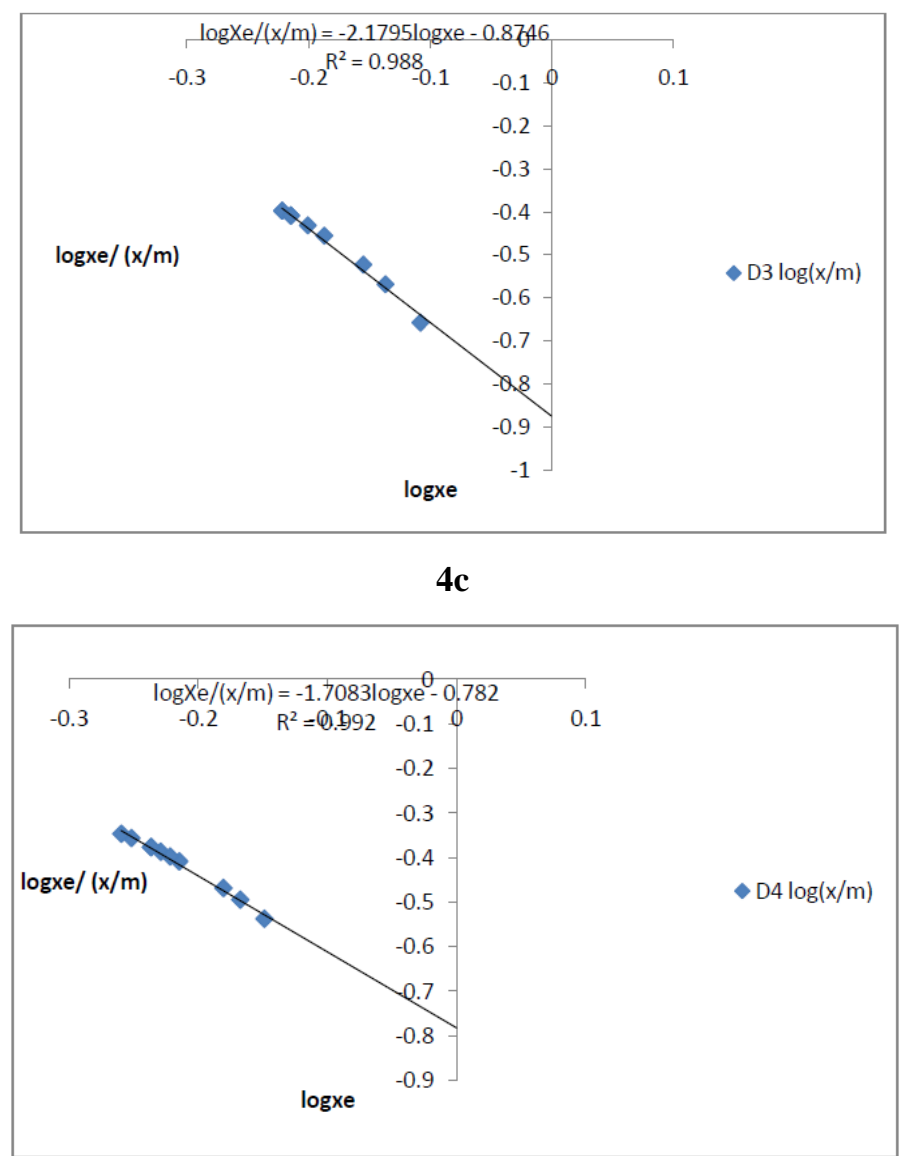

4d

Figure 4a-4d. Freundlich isotherm for cotton oil bleached using clay $D$

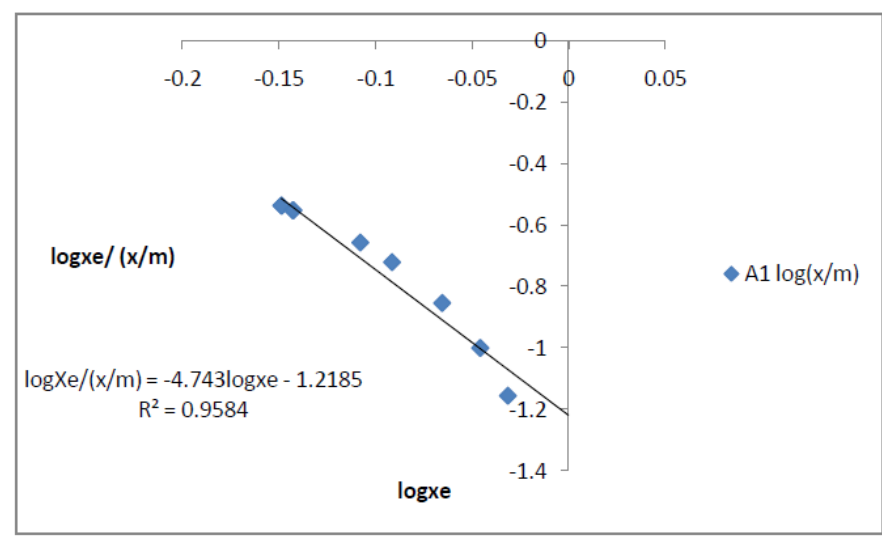

$5 a$

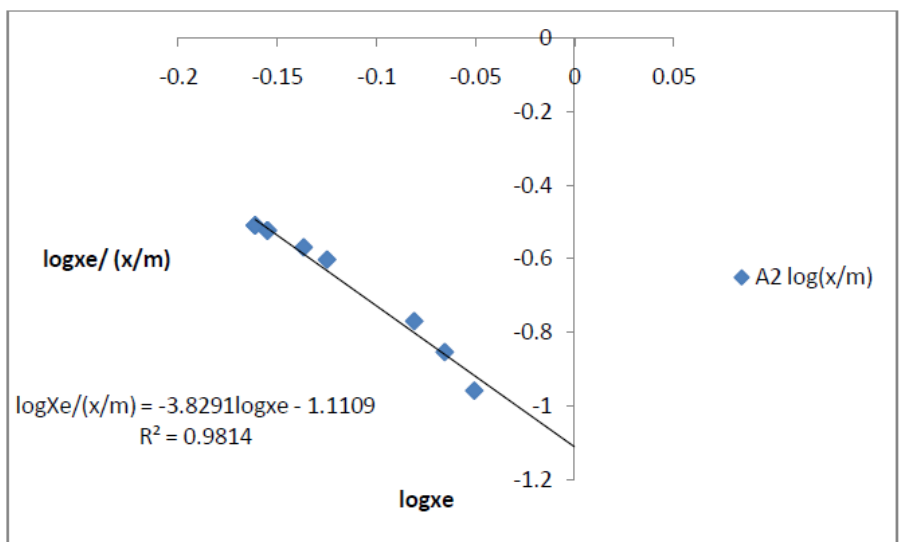

$5 b$ 


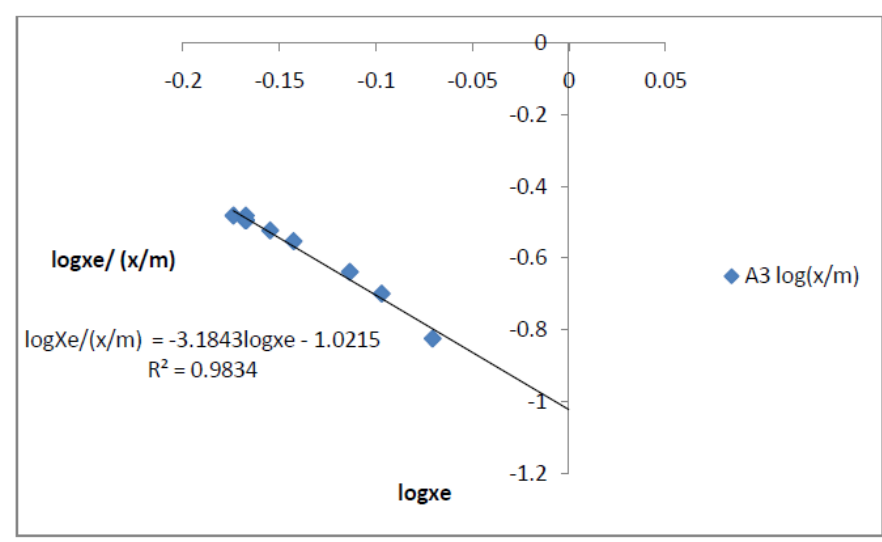

5 c

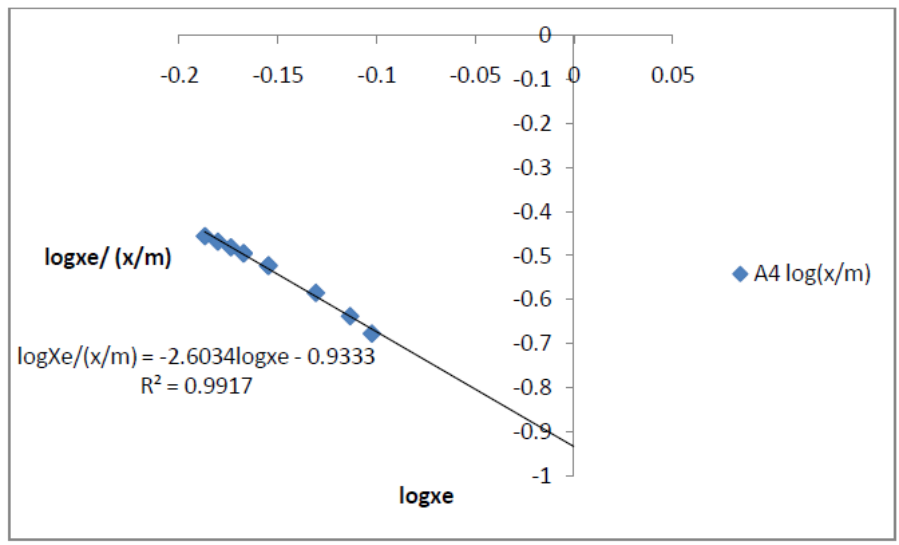

5d

Figures 5a-5d. Freundlich isotherm for sunflower oil bleached using clayA

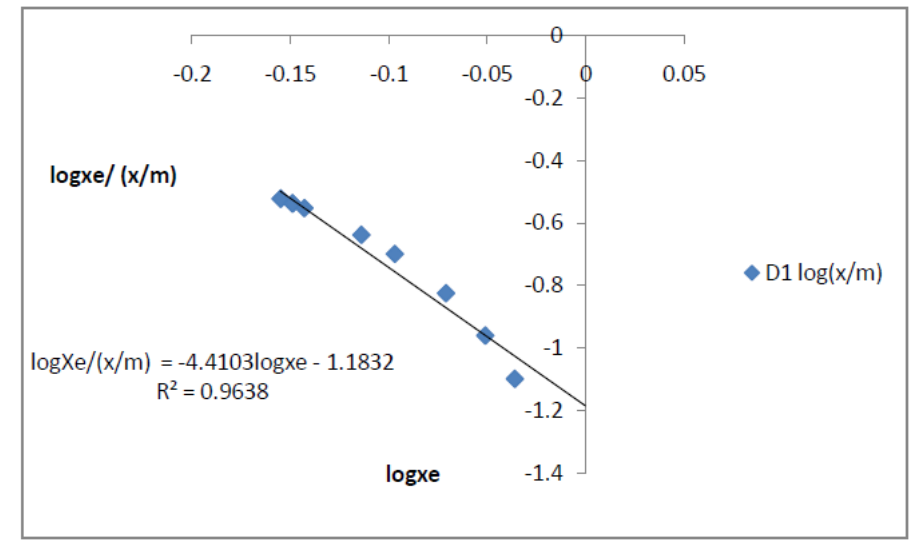

$6 a$

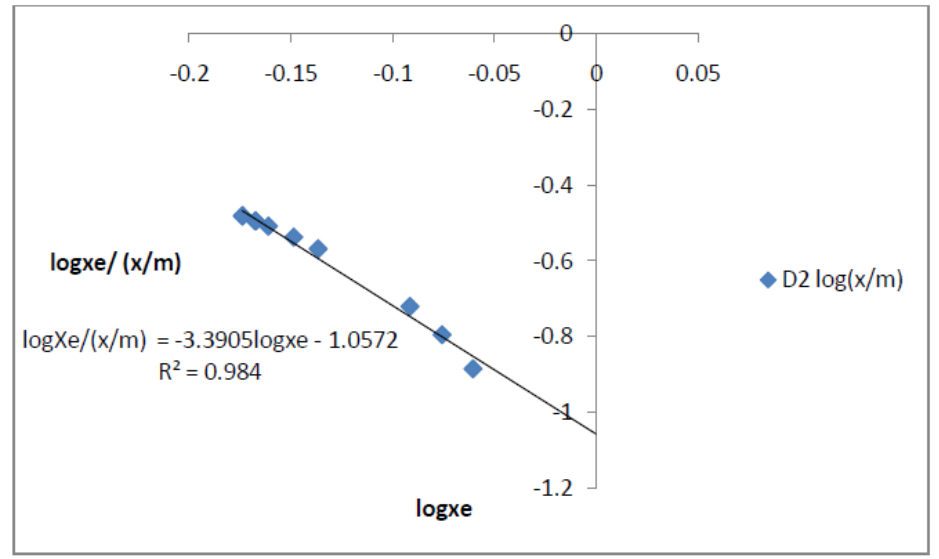

$6 b$ 


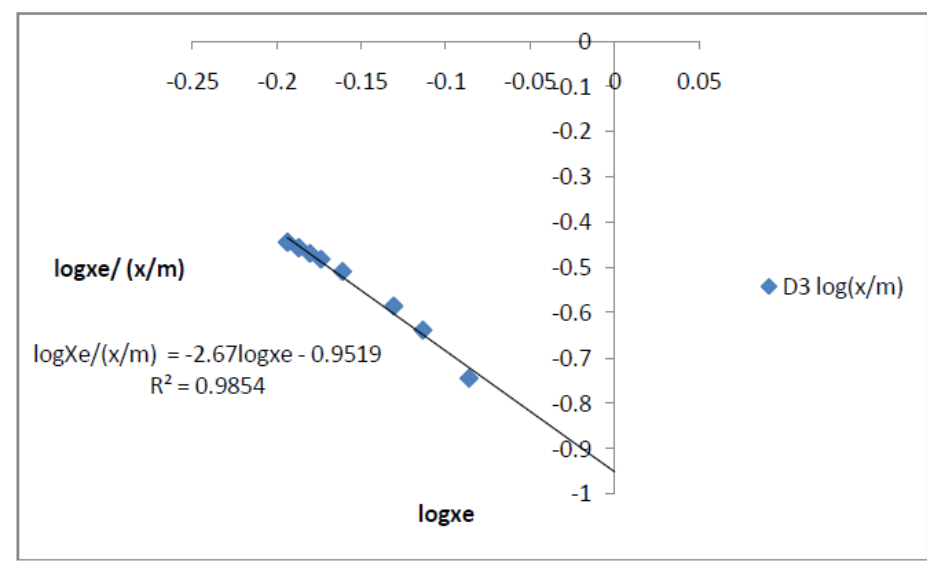

6c

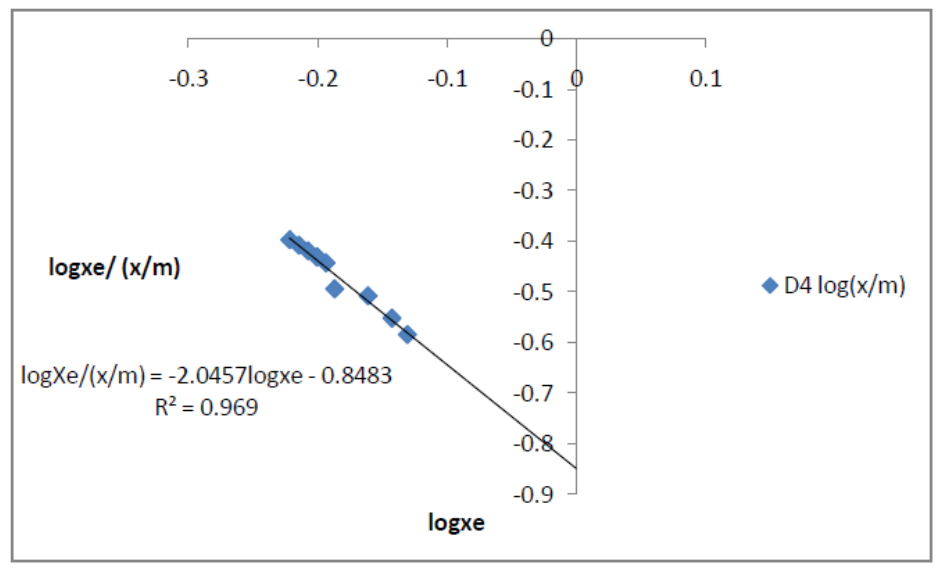

6d

Figures 6a-6d. Freundlich isotherm for sunflower oil bleached using D clay

The isotherms based on turbidity of bleached cotton and sunflower seed oils followed the Freundlich equation in much the same way as the decolorization of maize oil. This indicated the existence of heterogeneous adsorption sites on the solid's surface (Christidis and Kossairi, 2003).

The Figures 3a-3d, 4a-4d, 5a- 5b and 6a-6d show linearity in the temperature ranges between 40 and $110^{\circ} \mathrm{C}$ depicting that Freundlich isotherms are observed when adsorption occurs on clays if thermally activated at temperatures below $110^{\circ} \mathrm{C}$ (Topallar, 1998).

The extent of adsorption increased with temperature and clays leached with $25 \%$ acid showed highest adsorptive tendencies. The coefficients of linearity, expressed as $\mathrm{R}^{2}$ values for clay A increased from as low as $0.9484 \pm 0.017$ for A1 to as high as $0.9922 \pm 0.017$ for A4. This revealed the adsorptive capacity of clays was strongest when the clay had been leached in $25 \%$ sulfuric acid. This indicated that the capacity to bind colored impurities and suspended solids was high because of steric interferences between the adsorbed and free impurities present in vegetable oils being bleached was low (Travis and Etnier, 1981; Olsen and Watanabe; 1957).

The $\mathrm{R}^{2}$ values for clay D increased from as low as $0.9739 \pm 0.017$ for $\mathrm{D} 1$ to as high as $0.9739 \pm 0.017$ for $\mathrm{D} 4$ on cotton oils. Yet for sunflower oils it varied from $\mathrm{R}^{2}=0.9638 \pm 0.017$ to $0.969 \pm 0.017$. This revealed the adsorptive capacity of clays was strongest when the clay had been leached in $25 \%$ sulfuric acid. So the capacity of leached clay to bind colored impurities and suspended solids was high because of steric interferences between the adsorbed and free impurities present in vegetable oils did not set in during the bleaching process when these clays were used (Nodvin et al, 1986). The values of Freundlich constants $k$ and $n$ were calculated and listed for each clay with the linearized isotherm as shown below.

The Freundlich isotherms for cotton oils were;

$\operatorname{logXe} /(\mathrm{x} / \mathrm{m})=-4.952 \log \mathrm{xe}-1.2326, \mathrm{R}^{2}=0.9484, \mathrm{k}=-1.2326, \mathrm{n}=-4.952$ for $\mathrm{A} 1$.

$\log \mathrm{Xe} /(\mathrm{x} / \mathrm{m})=-3.9396 \log \mathrm{xe}-1.1198, \mathrm{R}^{2}=0.9776, \mathrm{k}=-1.1198, \mathrm{n}=-3.9396$ for $\mathrm{A} 2$.

International Journal of Advanced Research in Chemical Science (IJARCS)

Page $\mid 55$ 
$\operatorname{logXe} /(\mathrm{x} / \mathrm{m})=-3.2112 \log \mathrm{xe}-1.0239, \mathrm{R}^{2}=0.9803, \mathrm{k}=-1.0239, \mathrm{n}=-3.2112$ for $\mathrm{A} 3$.

$\operatorname{logXe} /(\mathrm{x} / \mathrm{m})=-2.5941 \log \mathrm{xe}-0.9332, \mathrm{R}^{2}=0.9922, \mathrm{k}=-0.9332, \mathrm{n}=-2.5941$ for A4.

$\log \mathrm{Xe} /(\mathrm{x} / \mathrm{m})=-4.621 \log \mathrm{xe}-1.1938, \mathrm{R}^{2}=0.9527, \mathrm{k}=-1.1938, \mathrm{n}=-4.621$ for $\mathrm{B} 1$.

$\operatorname{logXe} /(\mathrm{x} / \mathrm{m})=-3.4224 \log \mathrm{xe}-1.0598, \mathrm{R}^{2}=0.9805, \mathrm{k}=-1.0598, \mathrm{n}=-3.4224$ for $\mathrm{B} 2$.

$\log \mathrm{Xe} /(\mathrm{x} / \mathrm{m})=-2.6503 \log \mathrm{xe}-0.9454, \mathrm{R}^{2}=0.9848, \mathrm{k}=-0.9454, \mathrm{n}=-2.6503$ for $\mathrm{B} 3$.

$\operatorname{logXe} /(\mathrm{x} / \mathrm{m})=-1.9071 \log \mathrm{xe}-0.82, \mathrm{R}^{2}=0.9917, \mathrm{k}=-0.82, \mathrm{n}=-1.9071$ for $\mathrm{B} 4$.

$\log \mathrm{Xe} /(\mathrm{x} / \mathrm{m})=-4.2571 \log \mathrm{x}-1.1605, \mathrm{R}^{2}=0.9624, \mathrm{k}=-1.1605, \mathrm{n}=-4.2571$ for $\mathrm{C} 1$.

$\operatorname{logXe} /(\mathrm{x} / \mathrm{m})=-3.172 \operatorname{logxe}-1.0205, \mathrm{R}^{2}=0.985, \mathrm{k}=-1.0205, \mathrm{n}=-3.172$ for $\mathrm{C} 2$.

$\log \mathrm{Xe} /(\mathrm{x} / \mathrm{m})=-2.2978 \log \mathrm{e}-0.8938, \mathrm{R}^{2}=0.9867, \mathrm{k}=-0.8938, \mathrm{n}=-2.2978$ for $\mathrm{C} 3$.

$\log \mathrm{Xe} /(\mathrm{x} / \mathrm{m})=-1.7805 \log \mathrm{xe}-0.7952, \mathrm{R}^{2}=0.9881, \mathrm{k}=-0.7952, \mathrm{n}=-1.7805$ for $\mathrm{C} 4$.

$\log \mathrm{Xe} /(\mathrm{x} / \mathrm{m})=-3.3831 \log \mathrm{xe}-1.0607, \mathrm{R}^{2}=0.9739, \mathrm{k}=-1.0607, \mathrm{n}=-3.3831$ for $\mathrm{D} 1$.

$\log \mathrm{Xe} /(\mathrm{x} / \mathrm{m})=-2.8651 \log \mathrm{x}-0.9866, \mathrm{R}^{2}=0.9869, \mathrm{k}=-0.9866, \mathrm{n}=-2.8651$ for $\mathrm{D} 2$.

$\operatorname{LogXe} /(\mathrm{x} / \mathrm{m})=-2.1795 \mathrm{x}-0.8746, \mathrm{R}^{2}=0.988, \mathrm{k}=-0.8746, \mathrm{n}=-2.1795$ for $\mathrm{D} 3$.

$\operatorname{logXe} /(\mathrm{x} / \mathrm{m})=-2.1795 \log \mathrm{xe}-0.8746, \mathrm{R}^{2}=0.9739, \mathrm{k}=-0.8746, \mathrm{n}=-2.1795$ for $\mathrm{D} 4$.

The Freundlich isotherms for sunflower oil were ;

$\operatorname{logXe} /(\mathrm{x} / \mathrm{m})=-4.743 \operatorname{logxe}-1.2185, \mathrm{R}^{2}=0.9584, \mathrm{k}=-1.2185, \mathrm{n}=-4.4103$ for $\mathrm{A} 1$.

$\operatorname{logXe} /(\mathrm{x} / \mathrm{m})=-3.8291 \log \mathrm{xe}-1.1109, \mathrm{R}^{2}=0.9814, \mathrm{k}=-1.1109, \mathrm{n}=-3.1843$ for $\mathrm{A} 2$.

$\log \mathrm{Xe} /(\mathrm{x} / \mathrm{m})=-3.1843 \log \mathrm{xe}-1.0215, \mathrm{R}^{2}=0.9834, \mathrm{k}=-1.0215, \mathrm{n}=-3.1843$ for $\mathrm{A} 3$.

$\operatorname{logXe} /(\mathrm{x} / \mathrm{m})=-2.6034 \log \mathrm{xe}-0.9333, \mathrm{R}^{2}=0.9917, \mathrm{k}=-0.9333, \mathrm{n}=-2.6034$ for $\mathrm{A} 4$.

$\operatorname{logXe} /(\mathrm{x} / \mathrm{m})=-4.743 \log \mathrm{e}-1.2185, \mathrm{R}^{2}=0.9584, \mathrm{k}=-1.2185, \mathrm{n}=-4.743$ for $\mathrm{B} 1$.

$\operatorname{logXe} /(\mathrm{x} / \mathrm{m})=-3.5908 \log \mathrm{xe}-1.0827, \mathrm{R}^{2}=0.983, \mathrm{k}=-1.0827, \mathrm{n}=-3.5908$ for $\mathrm{B} 2$.

$\log \mathrm{Xe} /(\mathrm{x} / \mathrm{m})=-2.8043 \log \mathrm{xe}-0.9716, \mathrm{R}^{2}=0.9847, \mathrm{k}=-0.9716, \mathrm{n}=-2.8043$ for $\mathrm{B} 3$.

$\operatorname{logXe} /(\mathrm{x} / \mathrm{m})=-2.213 \log \mathrm{e}-0.8729, \mathrm{R}^{2}=0.9908, \mathrm{k}=-0.8729, \mathrm{n}=-2.213$ for $\mathrm{B} 4$.

$\log \mathrm{Xe} /(\mathrm{x} / \mathrm{m})=-4.2176 \log \mathrm{xe}-1.156, \mathrm{R}^{2}=0.967, \mathrm{k}=-1.156, \mathrm{n}=-4.2176$ for $\mathrm{C} 1$.

$\log \mathrm{Xe} /(\mathrm{x} / \mathrm{m})=-3.5226 \log \mathrm{xe}-1.0692, \mathrm{R}^{2}=0.9867, \mathrm{k}=-1.0692, \mathrm{n}=-3.5226$ for $\mathrm{C} 2$.

$\log \mathrm{Xe} /(\mathrm{x} / \mathrm{m})=-2.8187 \log \mathrm{xe}-0.9728, \mathrm{R}^{2}=0.984, \mathrm{k}=-0.9728, \mathrm{n}=-2.8187$ for $\mathrm{C} 3$.

$\log \mathrm{Xe} /(\mathrm{x} / \mathrm{m})=-2.3575 \log \mathrm{xe}-0.8962, \mathrm{R}^{2}=0.9925, \mathrm{k}=-0.8962, \mathrm{n}=-2.3575$ for $\mathrm{C} 4$.

$\log \mathrm{Xe} /(\mathrm{x} / \mathrm{m})=-4.4103 \log \mathrm{x}$ e- $1.1832, \mathrm{R}^{2}=0.9638, \mathrm{k}=-1.1832, \mathrm{n}=-4.4103$ for $\mathrm{D} 1$.

$\log \mathrm{Xe} /(\mathrm{x} / \mathrm{m})=-3.3905 \log \mathrm{xe}-1.0572, \mathrm{R}^{2}=0.984, \mathrm{k}=-1.0572, \mathrm{n}=-3.3905$ for $\mathrm{D} 2$.

$\operatorname{logXe} /(\mathrm{x} / \mathrm{m})=-2.67 \log \mathrm{e}-0.9519, \mathrm{R}^{2}=0.9854, \mathrm{k}=-0.9519, \mathrm{n}=-2.67$ for $\mathrm{D} 3$.

$\log \mathrm{Xe} /(\mathrm{x} / \mathrm{m})=-2.0457 \log \mathrm{xe}-0.8483, \mathrm{R}^{2}=0.969, \mathrm{k}=-0.8483, \mathrm{n}=-2.0457$ for $\mathrm{D} 4$.

The high linearity showed that the clay did not have limitations resulting from overcrowding, steric interference, thermodynamic instability at high impurity concentrations of adsorbate (Hundal, 1988). All clays used in this study have been described by the Freundlich isotherms within lower concentration ranges (Kothawala et al, 2008).

Freundlich adsorption isotherms assume monolayer adsorption capacity, multi layer sorption leads to deviation from linearity. Clays with low adsorption capacities easily deviated from linearity because they easily got saturated with impurities from oils causing steric interactions to occur between the adsorbed and unadsorbed impurities (Nodvin et al, 1986). If the clay got saturated with impurities, repulsion sets in which makes the isotherm non linear. As the Freundlich equation is valid for any color measurement method, provided the units are additive and proportional to the oil pigment concentration, so it has been possible to elucidate changes in turbidity using it.

If acid leached clays are activated at higher temperatures than $100^{\circ} \mathrm{C}$ changes their crystal structure is altered through loss of water. Loss of water may reduce capacity of clay to adsorb impurities, causing deviation from linearity. This is indicated by marked change in gradient and point of saturation. The values of the Freundlich constant $\mathrm{k}$ and $\mathrm{n}$ were obtained from plots of $\log \mathrm{Xe}(\mathrm{x} / \mathrm{m})$ against $\log \mathrm{Xe}$. The vertical intercept is $\mathrm{k}$ and slopes of the linear graphs is, $\mathrm{n}$ characterizing the bleaching power of the clay and the manner in which impurities adsorb on the clay respectively (Bijay, 2009; Boyd, 
1988; Norris, 1964; 1982). The larger the value of $k$ the higher bleaching performance of clays. The values of $\mathrm{k}$ for all clays increase with increase in strength of the acid used to leach the clay. Leaching with more concentrated acids resulted in creation of more adsorption sites in the resulting clay matrix. The highest ' $\mathrm{k}$ ' value obtained with clay $\mathrm{D}$ leached in $25 \%$ sulfuric acid. The $\mathrm{k}$ constant is a rough measure of the surface area of the adsorbent (Achife and Ibemesi, 1989). The value of the Freundlich constant $\mathrm{n}$ is used to determine the range of decolorization within which the adsorbent is most effective. An adsorbent with a higher value of $n$ will be relatively effective at binding impurities in oils, but inefficient at bleaching oil to a low color value (Achife and Ibemesi, 1989). The numerical value of $\mathrm{n}$ indicates a favorable sorption if less than unity (Gezici et al, 2007; Ahmaruzzaman et al, 2005; Zschau, 2001). The values of the Freundlich constants obtained in this study are very close to those obtained by Topallar (1998).

The values of $\mathrm{n}$ decreased with increase in leaching acid concentration due to proportionate increase in the bleaching strength of the clay (Gadzekpo et al, 1991). The differences in bleaching efficiency of the clays may be due to differences in the surface properties resulting from leaching clays (Falaras et al, 1999).

The Freundlich constant $\mathrm{k}$ increased with increase in temperature for both oils, showing that the formation of adsorptive sites on the clay rose. In this respect, the acid-activated clays behaved like the Turkish clay used in bleaching hazelnut oil (Yuksel, 2003).

The clay matrices used to bleach the oils were heterogeneous because they have Broensted and Lewis centers. In addition, they contain different phases of clays, such as kaolinite, nontronite and illite layers, which also have active centers on their surfaces. Similarly, heterogeneity of Cyprus bentonite was attributed both to different active Broensted and Lewis centers on the smectite surface and to the different phases present in clay, such as illitic layers and clinoptilolite, which also have active centers on their surfaces as the clay was a mixture of illite and bentonite (Christidis and Kossairi, 2003; Falaras et al, 1999).

Another brand of Freundlich isotherms is obtained by plotting the $\log _{\mathrm{e}}$ relative residual impurity concentration, $\ln \mathrm{Xe}$, against the reciprocal of the absolute temperature at which the bleaching process was performed. The data for this purpose has been presented in Tables $6 \mathrm{a}, 6 \mathrm{~b}, 7 \mathrm{a}$ and $7 \mathrm{~b}$. The Freundlich isotherms obtained by plotting data in Tables $6 \mathrm{a}, 6 \mathrm{~b}, 7 \mathrm{a}$ and $7 \mathrm{~b}$ are used to determine the enthalpy of adsorption.

Table6a. Representative Freundlich data for cotton oil bleached using clay A

\begin{tabular}{|l|l|l|l|l|}
\hline & A1 & A2 & A3 & A4 \\
\hline $1000 / \mathrm{T} \mathrm{K}^{-1}$ & $\ln \mathrm{Ne}$ & $\mathrm{lnXe}$ & $\ln \mathrm{Xe}$ & $\ln \mathrm{Xe}$ \\
\hline 3.1949 & -0.0737 & -0.1175 & -0.1626 & -0.2358 \\
\hline 3.096 & -0.1059 & -0.1508 & -0.2232 & -0.2614 \\
\hline 3.00300 & -0.1520 & -0.1863 & -0.2614 & -0.3012 \\
\hline 2.9154 & -0.2119 & -0.2876 & -0.3286 & -0.3567 \\
\hline 2.8328 & -0.2487 & -0.3148 & -0.3567 & -0.3858 \\
\hline 2.7548 & -0.3293 & -0.3567 & -0.3858 & -0.4157 \\
\hline 2.681 & -0.3431 & -0.3712 & -0.4005 & -0.4309 \\
\hline 2.611 & -0.3430 & -0.3712 & -0.4005 & -0.4005 \\
\hline 2.5445 & -0.3293 & -0.3567 & -0.3858 & -0.3858 \\
\hline 2.481 & -0.3293 & -0.3567 & -0.3858 & -0.3567 \\
\hline
\end{tabular}

Table6b. Representative Freundlich data for cotton oil bleached using clay D

\begin{tabular}{|c|c|c|c|c|}
\hline & D1 & D2 & D3 & D4 \\
\hline $1000 / \mathrm{T} \mathrm{K}^{-1}$ & $\ln x \mathrm{l}$ & $\ln x \mathrm{l}$ & $\ln \mathrm{e}$ \\
\hline 3.1949 & -0.1278 & -0.1743 & -0.2485 & -0.3425 \\
\hline 3.096 & -0.1626 & -0.2107 & -0.3148 & -0.3858 \\
\hline 3.00300 & -0.2107 & -0.2485 & -0.3567 & -0.4157 \\
\hline 2.9154 & -0.2745 & -0.3567 & -0.4309 & -0.4945 \\
\hline 2.8328 & -0.3148 & -0.3858 & -0.4622 & -0.5276 \\
\hline 2.7548 & -0.4005 & -0.4309 & -0.4945 & -0.5799 \\
\hline 2.681 & -0.4157 & -0.4463 & -0.5108 & -0.5979 \\
\hline 2.611 & -0.4157 & -0.4463 & -0.5108 & -0.5449 \\
\hline 2.5445 & -0.3858 & -0.4157 & -0.4945 & -0.5449 \\
\hline 2.481 & -0.3858 & -0.4157 & -0.4945 & -0.5108 \\
\hline
\end{tabular}

International Journal of Advanced Research in Chemical Science (IJARCS) Page | 57 
How Variation of Turbidity of Bleached Oils Characterizes Purity Oil and Bleaching Processes

Table7a. Representative Freundlich data for sunflower oil bleached using clay A

\begin{tabular}{|l|l|l|l|l|}
\hline & $\mathrm{A} 1$ & $\mathrm{~A} 2$ & $\mathrm{~A} 3$ & $\mathrm{~A} 4$ \\
\hline $1000 / \mathrm{T} \mathrm{K}^{-1}$ & $\ln \mathrm{xe}$ & $\ln \mathrm{e}$ & $\mathrm{ln} \mathrm{X}$ & $\ln \mathrm{xe}$ \\
\hline 3.1949 & -0.0725 & -0.1165 & -0.1626 & -0.2358 \\
\hline 3.096 & -0.1055 & -0.1508 & -0.2234 & -0.2614 \\
\hline 3.00300 & -0.1508 & -0.1863 & -0.2614 & -0.3012 \\
\hline 2.9154 & -0.2107 & -0.2876 & -0.2614 & -0.3567 \\
\hline 2.8328 & -0.2485 & -0.3148 & -0.3567 & -0.3858 \\
\hline 2.7548 & -0.3286 & -0.3567 & -0.3858 & -0.4157 \\
\hline 2.681 & -0.3425 & -0.3712 & -0.4005 & -0.4309 \\
\hline 2.611 & -0.3425 & -0.3712 & -0.3858 & -0.4005 \\
\hline 2.5445 & --0.3286 & -0.3567 & -0.3858 & -0.3858 \\
\hline 2.481 & -0.3286 & -0.3567 & -0.3858 & -0.3567 \\
\hline
\end{tabular}

Table7b. Representative Freundlich data for sunflower oil bleached using clay D

\begin{tabular}{|l|l|l|l|l|}
\hline & \multicolumn{1}{|c|}{ D1 } & \multicolumn{1}{c|}{ D2 } & \multicolumn{1}{c|}{ D3 } \\
\hline $1000 / \mathrm{T} \mathrm{K}^{-1}$ & $\ln \mathrm{Xe}$ & $\ln \mathrm{ne}$ & $\ln \mathrm{l}$ & \multicolumn{1}{c|}{ lnxe } \\
\hline 3.1949 & -0.0829 & -0.1393 & -0.1985 & -0.3012 \\
\hline 3.096 & -0.1175 & -0.1743 & -0.2614 & -0.3286 \\
\hline 3.00300 & -0.1635 & -0.2107 & -0.3012 & -0.3712 \\
\hline 2.9154 & -0.2234 & -0.3148 & -0.3712 & -0.4463 \\
\hline 2.8328 & -0.2625 & -0.3425 & -0.4005 & -0.4622 \\
\hline 2.7548 & -0.3431 & -0.3858 & -0.4309 & -0.4945 \\
\hline 2.681 & -0.3570 & -0.4005 & -0.4463 & -0.5108 \\
\hline 2.611 & -0.3570 & -0.4005 & -0.4463 & -0.4781 \\
\hline 2.5445 & -0.3431 & -0.3858 & -0.4309 & -0.4622 \\
\hline 2.481 & -0.3293 & -0.3712 & -0.4157 & -0.4309 \\
\hline
\end{tabular}

The data in Tables $6 \mathrm{a}, 6 \mathrm{~b}, 7 \mathrm{a}$ and $7 \mathrm{~b}$ show that there was increase in $\ln \mathrm{Xe}$ with increase in temperature and mass percent of acid used due to decrease in turbidity of oils caused by rise in the bleaching efficiency of the resulting clay matrix. This indicated that the energy released during bleaching would increase with bleaching temperature and mass percent of acid used to leach the clay. The data in Tables $6 a, 6 b, 7 a$ and $7 b$ was plotted to give Figures 7 to 10. In Figures 7 to10, the slopes are negative indicating the adsorption process was exothermic. The plots in Figures 7 to 10 are quite linear showing adsorption occurred to monolayer capacity without steric hindrances and interference. The representative linearized Freundlich isotherms have been summarily presented with the enthalpy of adsorption for each clay used in the study.

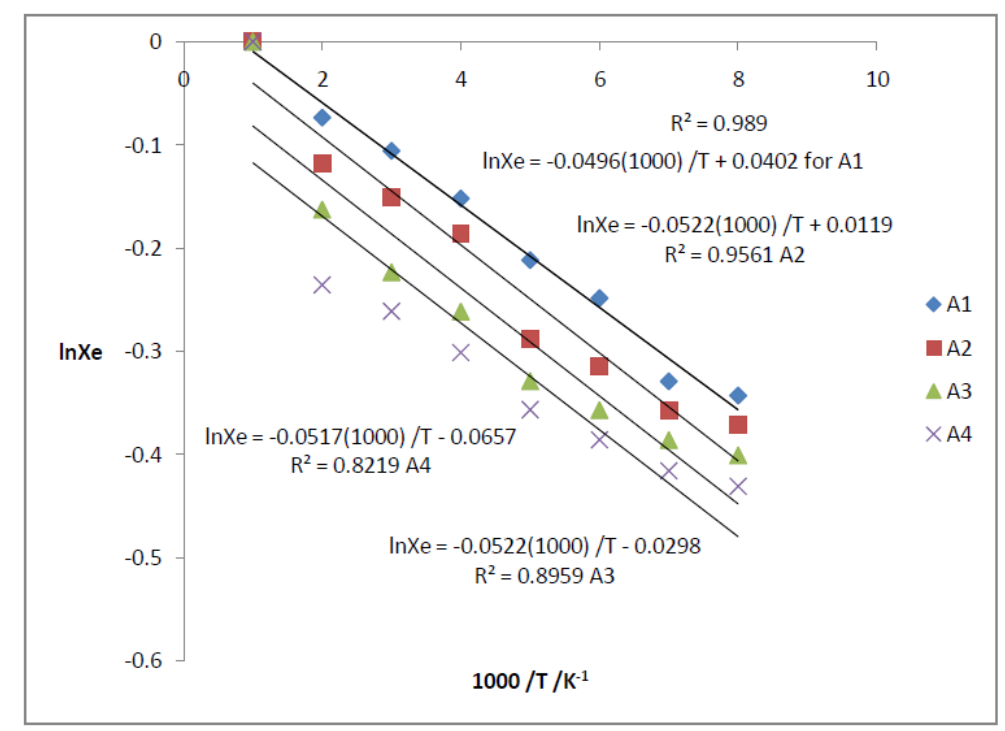

Figure7. Representative Freundlich isotherms for cotton oil bleached using clay A 


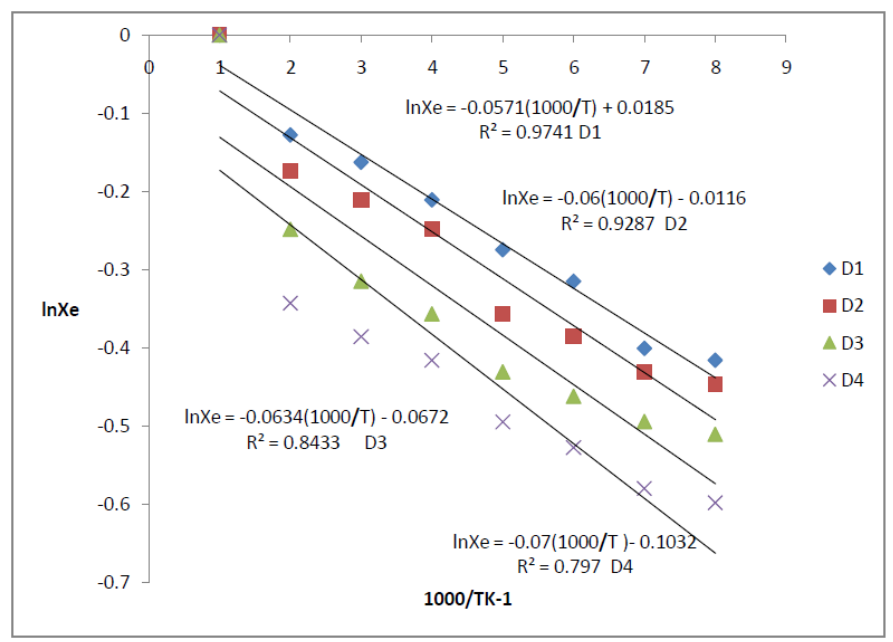

Figuere8. Representative Freundlich isotherms for cotton oil bleached using clay D

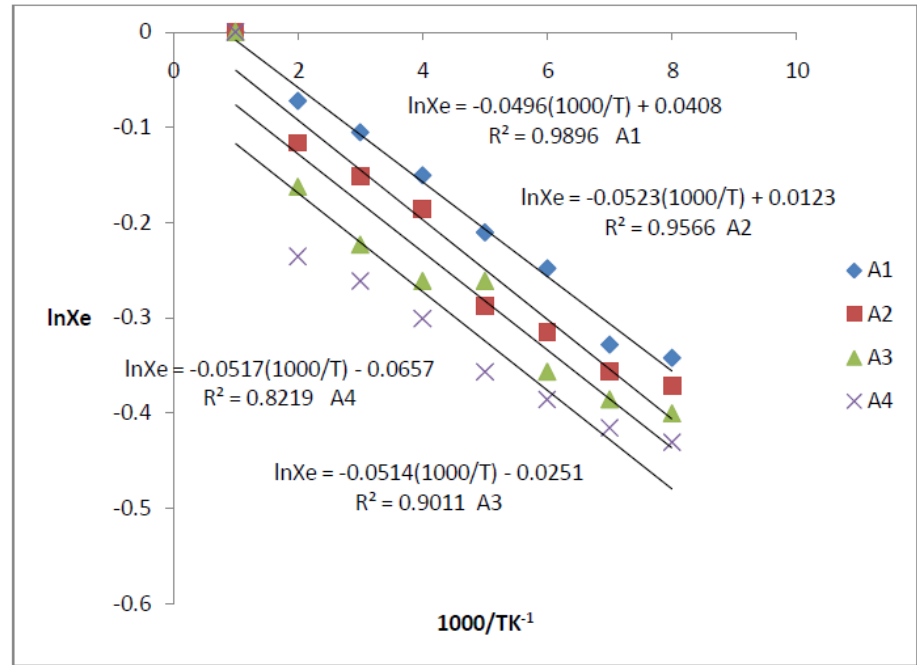

Figure9. Representative Freundlich isotherms for sunflower oil bleached using clay A

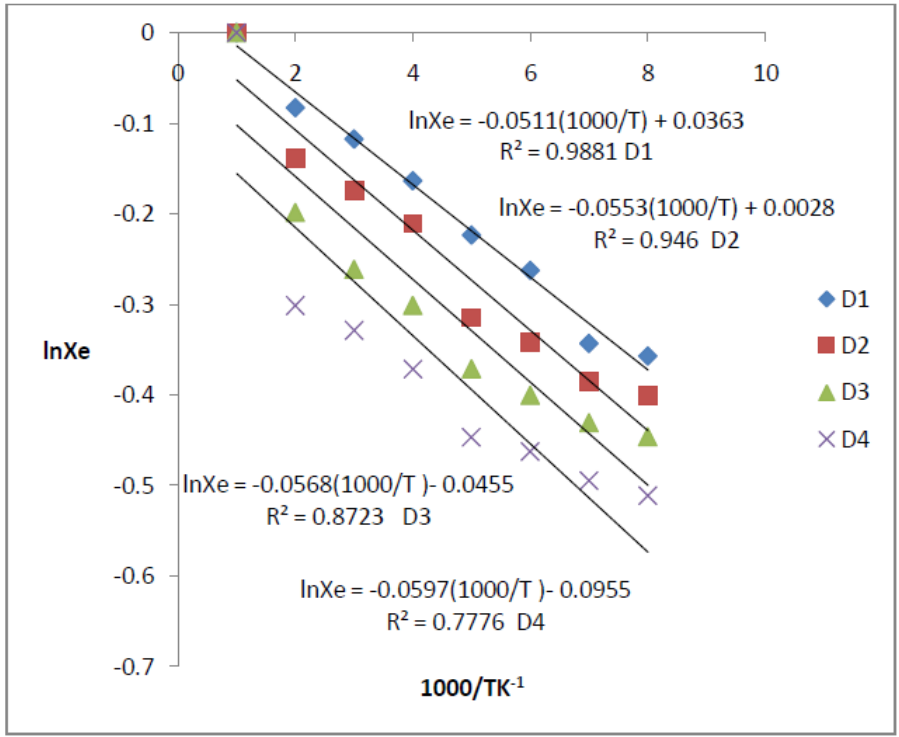

Figure10. Representative Freundlich isotherms for sunflower oil bleached using clay D

The Linearized Freundlich isotherms and enthalpy of adsorption are here presented for;

a) Cotton oil

$\ln \mathrm{Xe}=-0.0496(1000) / \mathrm{T}+0.0402 \mathrm{R}^{2}=0.9893, \Delta H a=-0.4124 \mathrm{kJmol}^{-1}$ for $\mathrm{A} 1$.

$\ln \mathrm{Xe}=-0.0522(1000) / \mathrm{T}+0.0119 \mathrm{R}^{2}=0.9561 \Delta H a=-0.4340 \mathrm{kjmol}^{-1}$ for $\mathrm{A} 2$.

International Journal of Advanced Research in Chemical Science (IJARCS) 


$$
\begin{aligned}
& \ln \mathrm{Xe}=-0.0522(1000) / \mathrm{T}-0.0298 \mathrm{R}^{2}=0.8959 \Delta H a=-0.4340 \mathrm{kJmol}^{-1} \text { for A3. } \\
& \ln \mathrm{Xe}=-0.0517(1000) / \mathrm{T}-0.0657 \mathrm{R}^{2}=0.8219 \Delta H a=-0.4298 \mathrm{kJmol}^{-1} \text { for } \mathrm{A} 4 \text {. } \\
& \ln \mathrm{Xe}=-0.0571(1000 / \mathrm{T})+0.0185 \mathrm{R}^{2}=0.9741 \Delta H a=-0.4747 \mathrm{kJmol}^{-1} \text { for D1 } \\
& \ln \mathrm{Xe}=-0.06(1000 / \mathrm{T})-0.0116 \mathrm{R}^{2}=0.9287 \Delta H a=-0.4988 \mathrm{kJmol}^{-1} \text { for } \mathrm{D} 2 \text {. } \\
& \operatorname{lnXe}=-0.0634(1000 / \mathrm{T})-0.0672 \mathrm{R}^{2}=0.8433 \Delta H a=-0.5271 \mathrm{kJmol}^{-1} \text { for } \mathrm{D} 3 \text {. } \\
& \operatorname{lnXe}=-0.07(1000 / \mathrm{T})-0.1032 \mathrm{R}^{2}=0.797 \Delta H a=-0.5820 \mathrm{kJmol}^{-1} \text { for } \mathrm{D} 4 . \\
& \operatorname{lnXe}=-0.0496(1000 / \mathrm{T})+0.0408 \mathrm{R}^{2}=0.9896, \Delta H a=-0.4124 \mathrm{kJmol}^{-1} \text { for } \mathrm{A} 1 \text {. } \\
& \ln \mathrm{Xe}=-0.0523(1000 / \mathrm{T})+0.0123 \mathrm{R}^{2}=0.9566 \Delta H a=-0.4348 \mathrm{kJmol}^{-1} \text { for A2 } \\
& \ln \mathrm{Xe}=-0.0514(1000 / \mathrm{T})-0.0251 \mathrm{R}^{2}=0.9011 \Delta H a=-0.4273 \mathrm{kJmol}^{-1} \text { for A3 } \\
& \operatorname{lnXe}=-0.0517(1000 / \mathrm{T})-0.0657 \mathrm{R}^{2}=0.8219 \Delta H a=-0.4298 \mathrm{kJmol}^{-1} \text { for } \mathrm{A} 4 \text {. } \\
& \ln \mathrm{Xe}=-0.0511(1000 / \mathrm{T})+0.0363 \mathrm{R}^{2}=0.9881 \Delta H a=-0.4248 \mathrm{kJmol}^{-1} \text { for D1 } \\
& \operatorname{lnXe}=-0.0553(1000 / \mathrm{T})+0.0028 \mathrm{R}^{2}=0.946 \Delta H a=-0.4598 \mathrm{kJmol}^{-1} \text { for } \mathrm{D} 2 \text {. } \\
& \ln \mathrm{Xe}=-0.0568(1000 / \mathrm{T})-0.0455 \mathrm{R}^{2}=0.8723 \Delta H a=-0.4722 \mathrm{kJmol}^{-1} \text { for } \mathrm{D} 3 \text {. } \\
& \ln \mathrm{Xe}=-0.0597(1000 / \mathrm{T})-0.0955 \mathrm{R}^{2}=0.7776 \Delta H a=-0.4963 \mathrm{kJmol}^{-1} \text { for D4. }
\end{aligned}
$$

The linearity $\mathrm{R}^{2}$ values for Freundlich isotherms in Figures 7 to 10 ranged from $0.778 \pm 0.030$ to $0.99 \pm$ 0.030 for bleaching of sunflower oils and $0.7970 \pm 0.030$ to $0.989 \pm 0.030$ for cotton oils.

For the clays used the linearity increased with mass percent of acid and temperature. As Freundlich adsorption isotherms assume monolayer adsorption capacity. Complications arise when clays and clays minerals exhibit multi-layer adsorption tendencies at high impurity concentrations; causing deviations from linearity of the isotherms plotted.

The Langmuir and Freundlich isotherms showed very high degree of linearity, it has been proposed that all clays developed very high adsorptive tendencies for the pigments and suspended solids in the oils being bleached. This coincides with information published by the European Group of Clay Analysts (Beneke and Lagaly, 2002), who reported that clay minerals or aluminosilicates in general, once acid-leached, turn into silica hydrate or silicic acid.

The heat of adsorption, $\triangle H a$, may be calculated using equation 1.9 given below;

$\ln X e=-\Delta H a / R T+c$

By plotting lnXe against the reciprocal (see Figures 7 to 10) of bleaching temperature and obtaining the slope of the graph, the heat of adsorption, $\triangle H a$, is given by product of slope and gas constant. The slopes of Figures 7 to 10 are negative indicating the adsorption of suspended solids and pigments from oils is exothermic.

The gradients of Figures 7 to 10 increased with concentration of the acid (Jadambaa et al, 2006) used to leach the clay depicting that acid-activation of the clay enhanced the bleaching capacity of any clay because the acid removed octahedral cations from the clay which retard bleaching (Balaras et al, 1999; Madejova, 2007). The heats of adsorption ranged from $-0.4124 \mathrm{kJmol}^{-1}$ to $-0.5820 \mathrm{~kJ} \mathrm{~mol}^{-1}$. Although the values obtained are less than those obtained for adsorption from gaseous phase, the fact that energy is evolved confirms the applicability of the Freundlich isotherms to the decolorization of cotton and sunflower seed oils (Ujeneza et al, 2014). The values enthalpies of adsorption obtained in this study were less than $20 \mathrm{~kJ} \mathrm{~mol}^{-1}$, indicating physical adsorption process occurred. This involves weak van der Waal's forces only (Topallar, 1998; Rich, 1964). The values enthalpies of adsorption are lower than expected because turbidity measurements may not be as thorough as absorbance at expressing the extent of adsorption during clay bleaching of vegetable oil.

\section{CONCLUSiOnS}

The following conclusions can be drawn from the results of this study:

Measurements of turbidity equally express the processes which take place during bleaching of cotton and sunflower seed oils as shown by the highly linear Freundlich and Langmuir isotherms obtained in this study. 
Clay D performed better than others because it was a mixture dioctahedral nontronite, quartz, feldspar, illite and kaolinite.

The bleaching efficiency of clays A, B, C, and D increased with concentration of acid used to activate the clay to a maximum value of $45 \%$ showing moderate acid concentration of $25 \%$ was low to achieve complete removal of octahedral ions from the clays.

The values of constants a, $\mathrm{b} \mathrm{k}$ and $\mathrm{n}$ as well as $\Delta H a$ obtained revealed the success of using turbidity of oils to describe the process of bleaching oils using clays.

\section{RECOMMENDATION}

The bleached oils h need to be tested for fitness for human consumption by measuring acid, free fatty acid, peroxide and trace metal values.

\section{ACKNOWLEDGEMENT}

We thank Mr. Rontgen Ruharara-Budigi for helping in cleaning and preparing samples. Prof G.W.A. Nyakairu for remarks made about the manuscript.

\section{REFERENCES}

[1] 4,000-year-old 'kitchen' unearthed in Indiana (2006). Archaeo News. January 26, 2006. Retrieved 201112-30.

[2] Achife E.C. and Ibemesi J.A. (1989). Applicability of the Freundlich and Langmuir adsorption isotherms in the bleaching of rubber and melon seed oils. J. Am. Chem. Soc., 66, 247-252.

[3] Ackman, R.G., S.N. Hooper, and D.L. Hooper(1974) Linolenic Acid Artifacts from the Deodorization of Oils, J. Am. Oil Chem. Soc. 51:42-49.

[4] Ahmaruzzaman M., Sharma D.K., Adsorption of phenols from wastewater. J. Colloid Interf. Sci., 2005, 287, 14-24.

[5] Ahrens, D., Comparison of Tray, Thin-film Deodorizing, INFORM 9:566-576 (1998).

[6] Alemdaroglu, T. (2003). Investigation of the Surface Acidity of a Bentonite Modified by Acid Activation and Thermal Treatment. Turk. J. Chem., 27, 675-683.

[7] Allen, B.L., Siltonen, P.H. and Thompson H.C.Jr. (1988).Determination of copper, lead, nickel in edible oils by plasma and furnace atomic absorption spectroscopy. J. Am. Oil Chemists Soc. 75, 477-481.

[8] Aro, A., J. van Amelsvoort, W. Becker, M.-A. van Erp-Baart, A. Kafatos, T. Leth, and G. Van Poppels, Trans Fatty Acids in Dietary Fats and Oils from 14 European Countries: The Transfair Study, J. Food Compos. Anal. 11:150-160 (1998).

[9] Basim, A. (2011). Rheology of sodium and calcium bentonite-water dispersions: Effect of electrolytes and aging time. Inter. Journal of Mineral Processing 98,208-213.

[10] Bain, C.D. and Nadeau, P.H. (1986). Composition of some smectite and diagenetic illite clays implications for their origin. Clay and Clay Minerals, 34(4) 455-464.

[11] Balaras, P. K., Lezou, P. and Seiragakis, G. (1999). Mineralogical Society of London: Clay Minerals, 34(2), 221-312.

[12] Ball, D.F.(1964). Loss on ignition as an estimate of organic matter and organiccarbon in non calcareous soils. The nature conservancy, Bangar Wales 85

[13] Beneke, K and Lagaly, G. (2002). From fuller's earth to bleaching earth: a historical note, European Clay Group Association Newsletter No 5. pp. 57-78.

[14] Bijay, K. D. J. D. P., Jignesh, B. P., Vijay K. P. and Vinay R. P. (2000). Activated Clay Journal of Oleo Science, 58, 257-263.

[15] Brigatti, M.F.; Galan, E. and B.K.G. Theng (2006). Developments in clay science: Handbook of clay science, in: M.F. Brigatti, E. Galan, B.K.G. Theng (Eds.), Structures and Mineralogy of Clay Minerals, 1, Elsevier, Oxford, pp. 19-86.

[16] Boki, K. M., Kubo, Twada and Tamura, N. (1992). Bleaching of alkali refined vegetable oils with clay minerals: J. Am. Oil Chem. Soc., 61, 233-236.

[17] Boki, K. M., Kawasaki, N. (1994). Bleaching of rape seed and soybean oils with synthetic adsorbents and attapulgites, J. Am. oil Chem. Soc. 71, 595-601.

[18] Boyd, S. A., Shaobai, S., Lee, J. F., and Mortland, M. M. (1988). Pentachlorophenol sorption by organoclays, Clays and Clay Minerals 36, 125-130.

[19] Car, R.A.(1978). Refining and degumming systems for edible oils and fats. J. Am. oil Chemists Soc. 55, 765-771.

[20] Caupeil, J.E. (1977) Emploi du laser pour mesure Ia limpidite des huiles. Rev. Fr. Corps Gras 24: 427-32.

International Journal of Advanced Research in Chemical Science (IJARCS)

Page | 61 
[21] Choe, E. and Min, D.B. (2006) Mechanisms and factors for edible oil oxidation. Comprehensive Reviews in Food Science and Food Safety. 5: 169-186.

[22] Christidis, G. E., Scott, P.W. and Marcopolous, T. (1995). Origin of bentonite deposits of Eastern Milos Islands , Greece:Geological, chemical and geochemical evidence. Clays and Clay Minerals 43(1), 63-77.

[23] Christidis, G. E., Kosiari, S. (2003). Decolorization of vegetable oils: A study of the mechanism of adsorption of $\beta$-carotene by an acid-activated bentonite from Cyprus. Clays and Clay Minerals, 51(3), 327333.

[24] Chu, Y.H and Lin, J.Y. (1993) Factors affecting the content of tocopherol in soy bean oil. J. Am. Oil Chern. Soc. 70: 1263-1268.

[25] Dandy, A. J. (1965). Bleaching vegetable oils with Kajansi, Koki and Mutaka clays. Proceedings of the East African Academy, 3, 2-8.

[26] Dandy, A. J.(1968). Bleaching cotton seed oils with a sepiolite: J.Phy.Chem 72,334-339.

[27] De Greyt, W. F., Kellens, M.J. and Huyghebaert, A.D. (1999): Effect of physical refining on selected minor components in vegetable oils. Lipid, 101, 428-432.

[28] Didi,M.A., B. Makhoukhi, A. Azzouz, and D. Villemin,(2009) Colza oil bleaching through optimized acid activation of bentonite: A comparative study, Applied Clay Science, 42, 336-344

[29] Donald,S.R. and K. Quirine (2012)Recommended methods for determining soil cation exchange capacity, http://extension.udel.edu/lawngarden/files/2012/10/CHAP9.pdf Retrieved on 11 September 2013

[30] Ejikeme,E.M; S.O. Egbuna, and P.C.N. Ejikeme (2013). Optimal bleaching performance of activated „Ngwulangwu“e clay, IJEIT, 3(5), 13-19

[31] Erickson, D.R., (199\$) Overview of Modern Soybean Processing and Links Between Processes, in Practical Handbook of Soybean Processing and Utilization, edited by D.R. Erickson, AOCS Press, Champaign, 62-64.

[32] Falaras, P. K.; Lezou, F. and Seiragakis, G.(1999). Cottonseed oil bleaching by acid-activated montmorillonite. Clay Minerals 34(2), 221-232.

[33] Farihahusnah,H.; K.A. Mohamed., and A.W.D. Wan Mohd,(2011). Textural characteristics, surface chemistry and activation of bleaching earth: A review, Chem. Eng. Jour. 170, 90-106

[34] Ferrari, R.A., E. Schulte, W. Esteves, L. Brühl, and K.D. Mukherjee(1996) Minor Constituents of Vegetable Oils During Industrial Processing, J. Am. Oil Chem. Soc.. 73:587-592

[35] Foletto,E.L; G.C. Colazzo, C. Volzone and L.M. Porto(2011). Sunflower oil bleaching by adsorption onto acid-activated bentonite. Brazilian Journal of Chemical Engineering 28(01), $169-174$.

[36] Freundlich, H.M.F. (1906) Über die Adsorption in Lösungen. Zeitschrift für Physikalische Chemie, 57 , $385-470$

[37] Fried, N., Shapiro, R.E. (1956). Phosphate supply patterns of various soils. Soil sci. Soc. Am. Proc. 20 , 471- 475 .

[38] Gadzekpo, V. P. Y., Mensah, S.G. (1991). Bleaching palm oiland shea butter oils using acid- leached Ghanaian clays. Ghana Journal of Chemistry and Industry, 1(4), 197-201.

[39] Gates, W.P., Anderson, J.S., Raven, M.D., and Churchman, G.J.,(2002) "Mineralogy of a bentonite from Miles, Queensland, Australia and characterization of its acid activation products", Appl. Clay Sci., 20, $189-197$.

[40] Gezici O., Kara H., Ayar A., and Topkafa M. (2007). Sorption behavior of Cu(II) ions on insolubilized humic acid under acidic conditions: An application of Scatchard plot analysis in evaluating the $\mathrm{pH}$ dependence of speci fic and nonspeci fic bindings. Sep. Purif. Technol., 55, 132-139.

[41] Gonzólez, E., Pradas, M., Villafranca Sónchez, M., Socías Viciana, A., Gallego, C.,(1994) “Adsorption of chlorophyll-a from acetone solution on natural and activated bentonite", J. Chem. Tech. Biotechnol., 61, $175-178$.

[42] Gregg, S.J. and Sing, K. S. W. (1982). Adsorption Surface Area and Porosity. London: Academic Press. 234- 243

[43] Gregg, S.J. and Sing, K.S.W. (1997). Adsorption, Surface Area and Porosity, Academic Press, London, 197-199.Guggenheim, S. and Martin, R.T. (1993). Definition of clay and clay mineral: Joint report of the AIPEA Nomenclature and CMS nomenclature committees 43(2) 255-256.

[44] Hua Liu, Roman Przybylski, N. A. Michael Eskin (1996). Turbidimetric measurement of haze in canola oil by acetone precipitation journal of the American Oil Chemists' Society 73(11), 1557-1560.

[45] Hassan, M.S., Abdel-Khalek, N.A.,(1998) Beneficiation and application of an Egyptian bentonite" Appl. Clay Sci., 13, 99-115. 
[46] Herzig, P.M., Humphris, S.E., Miller, D.J., and Zierenberg, R.A. (Eds.),(1998) Proceedings of the Ocean Drilling Program, Scientific Results, 158, 277 College station, Tx (Ocean drilling program).

[47] Hoffman G (1989) The Chemistry and Technology of Edible Oils and Fats and Their High Fat Products. Academic Press, Inc., San Diego, 139-200.

[48] Hui Y. (1996). Bailey's industrial oil and fat products. John Wiley and Sons Inc., New York 4, 281 -282.

[49] Hundal, H. S. (1988). Clays in soils of Maharana Partap. Journal of Agricultural Science, 111, 155-158.

[50] Jadambaa, T., Tsedev, J., Dashdendev, B., Shaarii, E. and Kenneth J. D M. (2006): Characterization and bleaching properties of acid-leached montmorillonite. Journal of Chemical Technology and Biotechnology, 81(4), 688-693.

[51] Jaroniec, M., Kruk, M. (1999). Standard Nitrogen Adsorption Data for Characterization of Nanoporous Silica. Langmuir, 15 (16), 5410-5413.

[52] Jeans, C. V., Merriman, R.J., and Mitchell, C. J.,. (1983). Significance of changes in clay mineralogy of jurassic sediments in France and England: Clay Mineralogy. , 12, 11-14.

[53] Jain VP, Proctor A, Lall R (2008a) Pilot-scale production of conjugated linoleic acid-rich soy oil by photoirradiation. J Food Sci 73(4): El83-E193.

[54] Jain VP, Tokle T, Kelkar S, Proctor A (2008b) Effect of the Degree of Processing on Soy Oil Conjugated Linoleic Acid Yields. JAg Food Chern 56: 8174-8178.

[55] Jawad IM, Kochhar SP, Hudson BJF (1983) Quality Characteristics of Physically Refined soybean oil: Effect of Pretreatment and Processing time and temperature. J. Food Technol.18: 353-360.

[56] Kardy, N, Sediek and Ashraf M. Amer. (2007). Sedimentaological and Technical studies on the Montmorillonitic clays of Abu Tartur Plateau, Western Desert, Egypt. Physiochem. Prob. of Min. Proc. 41, pp.89-99

[57] Kamal-Eldin A, Appelqvist L (1996) The chemistry and antioxidant properties oftocopherols and tocotrienols. Lipids 31: 671-701.

[58] Kara H., Ayyildiz H.F. and Topkafa M. (2008). Use of aminoprophyl silicaimmobilized humic acid for $\mathrm{Cu}$ (II) ions removal from aqueous solution by using a continuously monitored solid phase extraction technique in a column arrangement. Colloid Surface A, 312, 62-72.

[59] Kaviratna, H., Pinnavaia, T., (1994)“Acid hydrolysis of octahedral Mg2+ sites in 2 : 1 layered silicates: An assessment of edge attack and gallery access mechanisms”, Clays Clay Min., 42, 717_723.

[60] Kaynak G., Ersoz M., and Kara H.(2004). Investigation of the properties of oil at the bleaching unit of an oil refinery. J. Colloid Interf. Sci., 280, 131-138).

[61] Kellens, M.(1997). Current Developments in Oil Refining Technology, Technical Report De SmetBelgium, Antwerp, Belgium, 35-48.

[62] Kerr, P. F. (1952). Formation and occurrence of clay minerals. Clays and Clay Minerals. 1, 19-32.

[63] Kirabira, J.B.; Jounson, S. and Byaruhanga, J.K. (2005) Powder characterization of high temperature ceramic raw materials in the LakeVictoria region. Silicate industriels, 70(9-10) 127-134.

[64] Kothawala, D.N., Moore, T.R. and Hendershot, W.H. (2008). Adsorption of dissolved organic carbon to minerals. Comparison of isotherms approach. Geoderma 148, 43-50.

[65] Kutlic,G.B. and I. Sobota (2012). Bentonite processing, Professional Paper 24, 61-65

[66] Langmuir I.(1916), The constitution and fundamental properties of solids and liquids. Part I. Solids. J. Am. Chem. Soc. 38, 2221-2295.

[67] Leibovitz Z. and Ruckenstein, C. (1981). New Processes in Degumming, Bleaching, DeacidificationDeodorization and Winterizing of Edible Oils. Rev. Fr. Corps Gras, 28: 303-308.

[68] Leibovitz, Z. and Ruckenstein, C. (1984). Winterization of sunflower oil. J.Am. Oil Chern .Soc. 61(5): 870-872.

[69] Lindley, M.G. (1998). The impact of food processing on antioxidants in vegetable oils, fruits, and vegetables. Trends Food Sci. Technol. 9: 336-340.

[70] Lombardi, B.; Baschini, M.; Torres Sánchez, R.M.(2002). The surface area and CEC values of the samples studied. J. Arg. Chem. Soc., 90, 87 - 99.

[71] Longstaffe, F. J. (1981). Short courses in clays and Resources (Geology) 7, 245-450.

[72] Lagaly, G.(1995) In Clays Controlling the Environment; Churchman, G. D., Ed.; CSIRO Publishing; Melbourne, p 137.

[73] Makhoukhi, B., M.A. Didi, and D. Villemin(2008) Modification of bentonite with diphosphonium salts: Synthesis and characterisation. Mater. Lett. 62, 2493-2496.

International Journal of Advanced Research in Chemical Science (IJARCS)

Page | 63 
[74] Madejova, J., Bujjdak, J. A., Ceklovsky, J., Hrachova, J., Valuchova, J. and Komadel, P. (2007). Characterization of products obtained by acid leaching of Fe-bentonite: Clay Minerals, 42(4), 527-540.

[75] Mbah, B. J.M., Kamga J.F., Nguetnkam, J. and Fanni, J. (2005). Adsorption of pigments and free fatty acids from shea butter on activated Cameroonian clays. Eur. J. lipid Sci. Technol., 107, 307-394.

[76] Medina-Juárez,L.A., N. Gámez-Meza, J. Ortega-García, J. A. Noriega-Rodriguez, and Angulo-Guerrero, O. (2000) Trans fatty acid composition and tocopherol content in vegetable oils produced in Mexico J. Am. Oil Chem. Soc. 77(7) 721-724

[77] Morrison, W.H. and Robertson, J.A. (1975) Solvent Winterization of Sunflower Seed Oil. J.Am. Oil Chern. Soc. 52:148-150.

[78] Mukasa-Tebandeke, I.Z., Ssebuwufu, P.J.M., Nyanzi, S.A., Schumann, A., Nyakairu, G.W.A., Ntale, M. and Lugolobi, F. (2015). The Elemental, Mineralogical, IR, DTA and XRD Analyses Characterized Clays and Clay Minerals of Central and Eastern Uganda. Advances in Materials Physics and Chemistry, 5, 6786. http://dx.doi.org/10.4236/ampc.2015.52010

[79] Mukasa-Tebandeke, I.Z., Ssebuwufu, P.J.M., Lugolobi, F., Nyanzi, S., Schumann, A. and Ssekaalo, H. (2006). The Bleaching vegetable oils using acid and alkali-leached clays. International Journal of Environmental Issues, 2, 123-129

[80] Nadežda,S., L. Mihovil, L. Jelena, P. Jelena, M. Miljana, B. Biljana, and M. Radosavljevi, (2011) Characterization of bentonite clay from "Greda" deposit. Processing and Application of Ceramics 5 (2), 2011, 97-101.

[81] Nelson, D. L.; Cox, M. M.(2000) Lehninger, Principles of Biochemistry 3rd Ed. Worth Publishing: New York, 2000. ISBN 1-57259-153-6.

[82] Nguetnkam, J.P., Kamga, R., Villieras, F., Ekodeck, G.E. and Yvon, J. (2008) Assessing the Bleaching Capacity of Some Cameroonian Clays on Vegetable Oils. Applied Clay Science, 39, 113-121.

[83] Nomenclature of Lipids (2007). IUPAC-IUB Commission on Biochemical Nomenclature (CBN). Retrieved 2007-03-08

[84] Nodvin, S.C., Driscoll, C.T. and Likens, G.E. (1986). Simple partitioning of anions and dissolved organic carbon in soil. Soil Science, 142(1), 27-36

[85] Norris, F. A. (1982). Bailey's Industrial Oil and Fats Products, 4th Edn. New York: Wiley-Interscience.

[86] Norris, F. A. (1964). Bailey's Industrial Oil and Fats Products (3rd ed.). New York, NY, : Interscience.

[87] Nyakairu, G.W.A., Kurzweil, H. and Koeberl, C.(2002). Mineralogical, geochemical and sedimentalogical characteritics of clay deposits from Central Uganda and their applications Journal of African Earth Sciences, 35, 123-134.

[88] Olsen, R. S., Watanabe, F. S. (1957). A method to determine a phosphorous adsorption maximum of soils as measured by Langmuir isotherms. Soil Sci. Soc. Am. Proc. 21, 144-149.

[89] Parker, S.P. (1996) McGraw-Hill Dictionary of Earth Sciences. McGraw-Hill, New York.

[90] Parwez Saroj (2006) The Pearson Guide to the B.Sc. (Nursing) Entrance Examination. Pearson Education India. p. 109. ISBN 81-317-1338-5.

[91] Popov A, Dodova-Anghelova M, Ivanov CP, and Stefanov (1970) Further Investigations on the Composition of the Wax Isolated from Sunflower Husks. Riv. Ital. Sostanze Grasse 47: 254-256.

[92] Parker, S.P. (1996) McGraw-Hill Dictionary of Earth Sciences. McGraw-Hill, New York.

[93] Patterson, H. B. W. (1992). Bleaching and purifying fats and oils: theory and practice. American Oil Chemists' Society Press Proctor, A., Snyder, H .E. (1987). Adsorption efficiency of selected adsorbents in purification of phospholipids and lutein. J. Am. Oil Chem. Soc., 64, 1163

[94] Rabascall, N.H. and Riera, J.B. (1987) Variaciones del Contenido en Tocoferoles y Tocotrienoles Durante los Procesos de Obtenci6n e Hidrogenaci6n de Aceites Comestibles. Grasas Aceites 38:145-148.

[95] Rich, A.D. (1964). Adsorption of active isotopes from solution by soil. Soil Sci. Soc. Am. Proc. 21, 389392.

[96] Rich, A.D.(1960) Relationship between the apparent bulk density of a bleaching clay and its oil retention, JAOCS, 7(6),305-307

[97] Robin Dand (1999). The International Cocoa Trade. Woodhead Publishing. p169. ISBN 1-85573-434-6.

[98] Rossi,M.; Gianazza, M..; Alamprese,C.; and F. Stanga(2003). The role of bleaching clays and synthetic silica in palm oil physical refining, Food Chem. 82, $291-296$.

[99] Rossi, M., Gianazza, M., Alamprese, C., Stanga, F., (2001)“The effect of bleaching and physical refining on colour and minor components of palm oil”, J. Am. Oil Chem. Soc., 78, 1051-1055.

[100]Rožic,L., N. Tatjana, and P. Srđan(2010). Modeling and optimization process parameters of acid activation of bentonite by response surface methodology. Applied Clay Science 48, 154-158

International Journal of Advanced Research in Chemical Science (IJARCS)

Page | 64 
[101]Saadia M. Aly (1992). Degumming of soybean oil Vol. 43 Fase. 5, 284-286. (c) Consejo Superior de Investigaciones Científicas Licencia Creative Commons 3.0 España (by-nc) http://grasasyaceites. revistas. csic.es

[102] Sarier, N. and Güler, C.,(1988) " $\beta$-Carotene adsorption on acidactivated montmorillonite”, J. Am. Oil Chem. Soc, 65 (5), 776-790.

[103]Siddiqui, M. K. H. (1989). One of these physicochemical properties is surface acidity. Clay Miner., 37 , 385-395.

[104]Srasra, E., Bergaya, F.; van Damme, H. and N.K. Ariquib. (1989). Surface properties of activated bentonite decolorization of rape seed oils: Appl. Clay Sci., 4, 411-421.

[105]Srinivasan, K. R., Fogler, H. S. (1990). Adsorption of toxic organics on modified montmorillonite. Clay and Clay Minerals, 38(3) 287-293.

[106]Smith,J.M.(1970) Chemical Engineering Kinetics, 2nd Edn., McGraw-Hill Inc., New York.

[107]Topallar, H. (1998). Adsorption isotherms of the bleaching of sunfower-seed oil. Turk. J. Chem., 22, 143148.

[108]Topkafa, M.; H.; Ayyildiz, H.F. Arslan, N.F., Kucukkolbasi, S., Durmaz, F., SSen,S., and Kara, H.( 2013) Role of Different Bleaching Earths for Sun fl ower Oil in a Pilot Plant Bleaching System Pol. J. Food Nutr. Sci., 63(3), 147-154 DOI: 10.2478/v10222-012-0077-1 http://journal.pan.olsztyn.pl

[109]Tor A., Cengeloglu Y., Aydin M.E and Ersoz M. (2006). Removal of phenol from aqueous phase by using neutralized red mud. J. Colloid Interf. Sci. 300, 498-503.

[110]Travis, C. L., Etnier, E.L. (1981). A survey of sorption relationships for reactive solutes in soil. J. Environ. Quali. 10, 8-17.

[111]Turkulov, J., E. Dimic, Dj. Karlovic and V. Vuksa, (1986). The effect of temperature and wax content on the appearance of turbidity in sunflowerseed Oil. J. Am. Oil Chem. Soc., 63: 1360-1363.

[112]Ujeneza,E., Njenga,N.H., Mbui,N.D and Kariuki,N.D.(2014) Optimization of Acid Activation Conditions for Athi River Bentonite Clay and Application of the Treated Clay in Palm Oil Bleaching IOSR Journal of Applied Chemistry (IOSR-JAC) e-ISSN: 2278-5736. 7(8) I. 29-38 www.iosrjournals.org

[113]Usman,M.A.; O. Oribayo, A.A. Adebayo, (2013) Bleaching of Palm Oil by Activated Local Bentonite and Kaolin Clay from Afashio, Edo-Nigeria, Chemical and Process Engineering Research. 10, www.iiste.org

[114]Vanzuela-Diaz, F and Souza-Santos, P. (2001). Studies on the acid activation of Brazilian smectitic clays. quim. Nova, 24(3), 2001, 345-353 Research. 10, www.iiste.org

[115]Vandenbruwane, J., De Neve, S., Hofman, G., Sleutel, S. and Qualls R.G. (2007). Isotherm models for desired organic carbon (DOCS) and nitrogen sorption to mineral soil. Geoderma 139 144-153.

[116]Volotovskaya, S.N.; Sterlin, B.Y. and Zalevskaya, L.M. (1974). Some aspects of using phosphoric acids in refining of vegetable oils. Trudy Vsesoyuznogo Nauchno. 32:128

[117]Yuksel, B. (2003). Adsorption isotherms in bleaching hazelnut oil. J. Am. oil chemiststs' soc, 80(11), 1143-1146

[118]Zehnder, C.T., Deodorization, J. Am. Oil Chem. Soc. 77(7)240-244

[119]Zhansheng,W.U., Li, C., Sun, X., Xu, X., Dai, B., Li, J. and Zhao, H. (2006). Characterization, Acid Activation and Bleaching Performance of Bentonite from Xinjiang Chinese J. Chem. Eng., 14(2) 253258

[120]Zschau W., (2001). Bleaching of edible fats and oils. Eur. J. Lipid Sci. Tech., 103, 505-508.

Citation: M. Tebandeke I.Z et al., "How Variation of Turbidity of Bleached Oils Characterizes Purity Oil and Bleaching Processes", International Journal of Advanced Research in Chemical Science (IJARCS), vol. 4, no. 5, pp. 36-65, 2017. http://dx.doi.org/10.20431/2349-0403.0405005

Copyright: () 2017 Authors. This is an open-access article distributed under the terms of the Creative Commons Attribution License, which permits unrestricted use, distribution, and reproduction in any medium, provided the original author and source are credited. 